\title{
Two new genera of Lathrobiina from the East Palaearctic region (Coleoptera: Staphylinidae: Paederinae)
}

\author{
With 80 figures and 2 maps \\ VOLKER ASSING ${ }^{1}$ \\ ${ }^{1}$ Gabelsbergerstraße 2, 30163 Hannover, Germany. - vassing.hann@t-online.de \\ Published on 2013-12-20
}

\section{Summary}

Two genera of Lathrobiina are described, illustrated, and distinguished from Lathrobium GravENHORST, 1802 and allied genera: Elytrobium gen. n. (type species: Lathrobium monilicorne SHARP, 1889) and Sinlathrobium gen. n. (type species: Lathrobium lobrathiforme Assing, 2012). Elytrobium is distributed in the southeast of the East Palaearctic region and includes six species: E. monilicorne (SHARP, 1889), comb. n. (Japan); E. gongganum sp. n. (China: Gongga Shan); E. qinlinganum sp. n. (China: Qinling Shan); E. seminitidum sp. n. (China: Shaanxi); E. scindens sp. n. (China: Daba Shan); E. alesianum sp. n. (Taiwan). Sinlathrobium comprises four species from China: S. lobrathiforme (Assing, 2012), comb. n. (Yunnan); S. lobrathioides (Assing, 2012), comb. n. (transferred from Lathrobium) (Chongqing); S. densepunctatum sp. n. (Sichuan); S. iniquum sp. n. (Yunnan). Keys to the species of both genera are provided, and their distributions are mapped. Although all the species of both genera appear to be fully winged, four of the six Elytrobium and all the Sinlathrobium species have been recorded from only a single locality each. Three Elytrobium and three Sinlathrobium species are currently represented only by their respective holotypes.

\section{Key words}

Coleoptera, Staphylinidae, Paederinae, Lathrobiina, Elytrobium, Sinlathrobium, Lathrobium, Lobrathium, Tetartopeus, East Palaearctic region, China, Taiwan, Japan, taxonomy, new genera, new species, new combinations, key to species, distribution maps

\section{Zusammenfassung}

Zwei Gattungen aus der Subtribus Lathrobiina werden beschrieben, abgebildet und von Lathrobium GrAVENHORST, 1802 und verwandten Gattungen unterschieden: Elytrobium gen. n. (Typusart: Lathrobium monilicorne SHARP, 1889) und Sinlathrobium gen. n. (Typusart: Lathrobium lobrathiforme Assing, 2012). Elytrobium ist mit sechs Arten in der südöstlichen Ostpaläarktis verbreitet: E. monilicorne (SHARp, 1889), comb. n. (Japan); E. gongganum sp. n. (China: Gongga Shan); E. qinlinganum sp. n. (China: Qinling Shan); E. seminitidum sp. n. (China: Shaanxi); E. scindens sp. n. (China: Daba Shan); E. alesianum sp. n. (Taiwan). Die Verbreitung der vier Sinlathrobium-Arten beschränkt sich auf China: S. lobrathiforme (Assing, 2012), comb. n. (Yunnan); S. lobrathioides (Assing, 2012), comb. n. (vorher Lathrobium) (Chongqing); S. densepunctatum sp. n. (Sichuan); S. iniquum sp. n. (Yunnan). Für beide Gattungen werden Bestimmungstabellen erstellt; ihre Verbreitung wird anhand von Karten illustriert. Obwohl wahrscheinlich alle Arten beider Gattungen voll ausgebildete Flügel besitzen, sind vier der sechs Elytrobium- und alle Sinlathrobium-Arten lediglich von jeweils einem Fundort bekannt. Drei Elytrobium- und drei Sinlathrobium-Arten sind derzeit lediglich durch die jeweiligen Holotypen vertreten. 


\section{Introduction}

According to Coiffait (1982) and Smetana (2004), the paederine subtribe Lathrobiina LAPORTE, 1835 is represented in the Palaearctic region by twelve genera: Achenium LeACH, 1819, Domene Fauvel, 1873, Lathrobium Gravenhorst, 1802, Lobrathium Mulsant \& Rey, 1878, Platydomene Ganglbauer, 1895, Pseudobium MulSant \& Rey, 1878, Pseudolathra Casey, 1905, Tetartopeus Czwalina, 1888, Throbalium Mulsant \& Rey, 1878, Micrillus Raffray, 1873, Scymbalium Erichson, 1839, and Scymbalopsis ReItTer, 1909. Preliminary revisionary studies of Micrillus and Scymbalium from the Palaearctic, the Afrotropical, and the Oriental regions suggest, however, that these genera (probably also Scymbalopsis) are not closely related to Lathrobium and allied genera and may belong to a separate subtribe (Assing in press b). Recently, another genus, Nipponolathrobium, including five species from Japan, was described by WATANABE (2012). However, the morphological details and illustrations provided with the description suggest that this taxon may be synonymous with Domene. Based on personal observations and on the characters illustrated and described by Rougemont (1997), Dysanabatium BerNHAUER, 1915, a genus listed as Paederinae incertae sedis by Smetana (2004) and distributed in the Oriental and southern East Palaearctic regions, probably belongs to Lathrobiina, too.

According to Newton et al. (2001), three additional genera from the Nearctic and Neotropical regions have been attributed to the Lathrobiina. One of them was synonymized recently, thus leaving two genera: Dacnochilus LeConte, 1861 and Paederopsis Wasmann, 1912.

A comprehensive phylogenetic study of the Lathrobiina has never been attempted. Traditionally, the genera have been distinguished based on morphological characters such as the shape of the head, the presence/absence of a supramarginal line of the elytra, the width of the posterior constriction of the head, the length of metatarsomere I, the punctation of the elytra, the presence/absence of long setae on the tibiae, the presence/absence of a median carina on the abdominal sternite III, and the position of the aedeagus in the abdomen (CoIfFAIt 1982). However, at least some of these characters may be subject to intrageneric variation. For instance, the supramarginal line of the elytra that has been regarded has an important character separating Lobrathium from Lathrobium was found to be absent in some micropterous Lobrathium species from Taiwan (Assing 2010a).

While some genera such as Achenium, Pseudobium, Throbalium, and Tetartopeus are well-defined and readily identified, others are weakly delimited due to the absence of clear-cut synapomorphies separating them. This is particularly true of Lobrathium, Platydomene, and Domene, which are usually distinguished based on - occasionally overlapping - characters related to their habitus.

In the course of recent revisions of several lathrobiine genera (Achenium, Lathrobium, Lobrathium, Pseudolathra, Pseudobium, Tetartopeus) from the Palaearctic and Oriental regions (e.g. Assing 2009, 2010a, b, 2011, 2012a, b, 2013a, b, in press a), nine species represented by only few specimens, most of them found in material from the collections of Aleš Smetana (Ottawa) and Michael Schülke (Berlin), were discovered that did not seem to fit into any of the known genera of Lathrobiina. Two of them were tentatively described in the genus Lathrobium (Assing 2012a). A tenth species was recently seen while revising type material of some Lathrobium species described by SHARP (1889) from Japan (Assing in press a). Based on a comparative study of morphological characters, they are hypothesized to represent two undescribed genera.

\section{Material and methods}

The material treated in this study is deposited in the following public institutions and private collections:

\section{BMNH The Natural History Museum, London (R. G. Booth) \\ NMP National Museum of Natural History, Praha (J. Hájek) \\ cAss author's private collection \\ cSch private collection Michael Schülke, Berlin \\ cSme private collection Aleš Smetana, Ottawa}

The morphological studies were conducted using a Stemi SV 11 microscope (Zeiss Germany) and a Jenalab compound microscope (Carl Zeiss Jena). A digital camera (Nikon Coolpix 995) was used for the photographs. The maps were created using MapCreator 2.0 (primap) software.

Body length was measured from the anterior margin of the mandibles (in resting position) to the abdominal apex, the length of the forebody from the anterior margin of the mandibles to the posterior margin of the elytra, head length from the anterior margin of the frons to the posterior margin of the head, elytral length at the suture from the apex of the scutellum to the posterior margin of the elytra (at the suture), and the length of the aedeagus from the apex of the ventral process to the base of the aedeagal capsule. The "parameral" side (i.e., the side where the sperm duct enters) is referred to as the ventral, the opposite side as the dorsal aspect. 


\section{Elytrobium gen. n.}

\section{Type species: Lathrobium monilicorne SHARP, 1889}

\section{Etymology:}

The name (gender: neuter) is composed of the Greek word elytron and the ending of the generic name Lathrobium. It alludes to the long elytra combined with a habitus somewhat resembling species of Lathrobium.

\section{Description:}

Species of relatively small to moderate size; body length 5.2-7.8 $\mathrm{mm}$; length of forebody 3.0-4.0 $\mathrm{mm}$. Habitus as in Figs 1, 7, 14, 22. Coloration dark, body usually black, rarely dark-brown; legs and antennae at least partly paler.

Head (e.g., Figs 2, 8, 15, 23) rather small in relation to body and slender, oblong, mostly broadest across eyes, and more or less distinctly tapering behind eyes; posterior angles rounded, noticeable or obsolete; neck approximately half the width of head; punctation on dorsal surface distinct; interstices with microreticulation; ventral aspect (Fig. 32) strongly, rugosely sculptured, matt, and with shallow punctures; gular sutures broadly separated; genal carinae absent. Eyes convex, composed of numerous fine ommatidia, and at least as long as half distance from posterior margin of eye to neck. Antenna (Figs 16, 24, 47) moderately slender; antennomeres V-X about as long as broad or weakly oblong. Maxillary palpomere III of variable morphology, slender to conspicuously dilated, 2.0-3.5 times as long as broad. Labial palpus (Fig. 42) short, with weakly oblong palpomeres I and II, and with relatively short palpomere III. Mandibles (Fig. 40) as in Lathrobium. Labrum (Fig. 41) distinctly, but not very deeply bilobed.

Pronotum (e.g., Figs 2, 8, 15, 23) moderately oblong, mostly widest in posterior half, broader than head, and strongly convex in cross-section; posterior angles weakly marked; punctation distinct and dense; impunctate midline narrow; interstices with or without microsculpture. Prosternal process long and very acute.

Elytra (e.g., Figs 2, 8, 15, 23) conspicuously long and broad in relation to pronotum; supramarginal line absent; punctation distinct, irregular or arranged in indistinct series. Hind wings fully developed. Ventral aspect of meso- and metathorax as in Lathrobium. Protarsomeres I-IV distinctly dilated in both sexes. Metatarsomere I approximately as long as II.

Abdomen narrower than elytra; punctation dense and distinct on anterior tergites, gradually becoming finer and sparser towards the abdominal apex; tergite VII with palisade fringe; tergite VIII without sexual dimorphism and with truncate posterior margin; sternite III with long and pronounced median keel extending over the full length of sternite; sternites III-VI without sexual dimorphism; tergites IX and $\mathrm{X}$ without sexual dimorphism, tergite IX long, slender, and undivided in the middle, postero-lateral processes apically with spine-like process (Fig. 39); tergite $\mathrm{X}$ small, much shorter than antero-median portion of tergite IX (Fig. 39).

$0^{\text {: }}$ : sternite VII (e.g., Figs 3, 9, 17, 25) weakly modified, without distinct impression and with unmodified pubescence; sternite VIII (e.g., Figs 4, 10, 18, 26) with shallow posterior excision, otherwise unmodified; sternite IX (Figs 11, 19, 27, 35, 50) symmetric and anteriorly acute; aedeagus (Figs 5-6, 12-13, 20-21, 28-29, 36-37, 51-55) small in relation to body and distinctly asymmetric; ventral process somewhat twisted, with the right margin projecting ventrad and the left margin dorsad in ventral view, subapically curved, and apically usually more or less distinctly hooked in lateral view; dorsal plate weakly sclerotized, narrow, and lamellate; internal sac devoid of sclerotized structures; parameres absent.

i : sternite VIII with convex posterior margin, posterior portion with micropubescence (Figs 56-57).

\section{Comparative notes:}

Among the Lathrobiina, the new genus is readily identified by external characters alone, particularly the small, oblong, distinctly microsculptured, and posteriorly more or less distinctly tapering head combined with dark coloration, and long elytra. In addition, it is characterized by weakly modified male sternites VII and VIII, as well as by a distinctive shape of the aedeagus without sclerotized internal structures.

Among the genera currently attributed to the Lathrobiina, Elytrobium has some resemblance only to Lathrobium and some genera treated as subgenera of Lathrobium until several decades ago, in particular Tetartopeus and Lobrathium. Aside from the characters pointed out above, Elytrobium differs from the latter by the absence of a supramarginal line of the elytra. Regarding its head shape, Elytrobium is most similar to Tetartopeus, from which it is distinguished by the broader neck (Tetartopeus: neck distinctly less than half the width of head), by the completely different secondary sexual characters in both sexes, and by the completely different morphology of the aedeagus (Tetartopeus: aedeagus symmetric, with long, slender, and apically acute ventral process, with distinctly larger and more sclerotized dorsal plate, and with dark internal structures). For illustrations of Tetartopeus see Assing (2009, 2011).

Using the key to paederine genera in CoIfFAIt (1982), Elytrobium would key out together with Lathrobium, the most speciose of all genera of Lathrobiina. Based on revisionary studies of Lathrobium from both the West and the East Palaearctic region, it is concluded that Elytrobium represents a distinct lineage. Despite a slight resemblance with some macropterous Lathrobium species, Elytrobium differs morphologically in 
numerous and significant respects: head smaller and posteriorly usually tapering; ventral aspect of head conspicuously sculptured and with broadly separated gular sutures; labrum less deeply bilobed; labial palpus shorter and with less oblong palpomeres; pronotum of different shape (Lathrobium: pronotum with subparallel lateral margins or widest in anterior half); prosternal process longer and more acute; elytra conspicuously long; median keel of sternite III long; absence of a sexual dimorphism of tergites VIII-X; male sternites VII and VIII weakly modified; morphology of the aedeagus characteristic, internal structures absent. For illustrations of the labrum and the labium of the type species of Lathrobium, L. elongatum (Linnaeus, 1767), see Figs 43-44. In all the previously revised Lathrobium species the abdominal tergites IX and $\mathrm{X}$ are subject to a pronounced sexual dimorphism, most likely one of the main synapomorphies constituting the monophyly of the genus. In some species (groups) the aedeagus may be of highly derived morphology and lack internal structures. Likewise, some species (groups) have weakly modified male sternites VII and VIII. These conditions, however, undoubtedly represent secondary reductions and are not homologous to the condition in Elytrobium. Moreover, the male sternite IX in Lathrobium is mostly less acute anteriorly and more or less asymmetric, particularly so in species with an asymmetric aedeagus. Finally, the available data suggest that Elytrobium differs from Lathrobium also regarding its natural history. The vast majority of Lathrobium species inhabits the leaf litter layer of shrub and forest habitats or lives epigeically in unforested habitats such a lake shores, river banks, and arable land. However, the genus also includes numerous microphthalmous or anophthalmous, micropterous, and depigmented species with a hypogean habitat. For notes on Elytrobium see the following section.

\section{Distribution and natural history:}

The currently known distribution of Elytrobium is confined to the East Palaearctic: China, Taiwan, and Japan (Map 1). All the species of this genus have long elytra, fully developed hind wings, and are probably capable of flight. Nevertheless, they have been found only on very rare occasions. Except for E. monilicorne (two specimens), no more than one specimen was found in one locality, and three of the six species are represented only by singletons. These observations suggest that the Elytrobium species inhabit a special, cryptic habitat and are recorded only by coincidence. The specimens collected by Aleš Smetana (three species) were found in moss, leaf litter, and vegetation in moist to wet habitats, one was captured with a yellow pan trap.

\section{Elytrobium monilicorne (SHARP, 1889), comb. $\mathrm{n}$ (Figs 1-6, Map 1)}

Lathrobium monilicorne SHARP, 1889: 259.

\section{Type material examined:}

Lectotype $0^{\star}$ : "Lathrobium monilicorne. Type D. S., Fuji. Japan. Lewis, an gen. nov. [handwritten on mounting label] / Sharp Coll, 1905-313 / Aedeagus at rest turned to $90^{\circ}$ in abdomen / Lathrobium monilicorne Sharp, V.I. Gusarov det. 1992 / Lectotypus o Lathrobium monilicorne Sharp, desig. V. Assing 2013 / Elytrobium monilicorne (Sharp), det. V. Assing 2013" (BMNH). Paralectotype $0^{*}$ : "Lathrobium monilicorne. D. S., Fuji. [handwritten on mounting label] / Japan. G. Lewis. 1910-320. / Sharp Coll, 1905-313 / Lathrobium monilicorne Sharp, V. I. Gusarov det. 1992 / Paralectotypus o Lathrobium monilicorne Sharp, desig. V. Assing 2013 / Elytrobium monilicorne (Sharp), det. V. Assing 2013” (BMNH).

\section{Comment:}

For details on the type material and on the lectotype designation see Assing (in press a).

\section{Description:}

Body length 7.0-7.5 mm; length of forebody 3.4-3.7 mm. Habitus as in Fig. 1. Coloration: body blackish; legs with the femora blackish-brown, the tibiae dark-brown, and the tarsi pale-brown; antennae reddish-brown with antennomere I infuscate; maxillary palpi pale-reddish.

Head (Fig. 2) rather small in relation to body, approximately 1.05 times as long as broad, weakly tapering behind eyes; posterior angles rounded, but noticeable; neck approximately half the width of head; punctation coarse and dense, slightly sparser in median dorsal portion; interstices narrower than diameter of punctures, with microreticulation, and subdued shine. Eyes moderately large and composed of numerous fine ommatidia, approximately 0.6 times as long as postocular region from posterior margin of eye to neck in dorsal view. Antenna 1.7-1.8 mm long; antennomeres IV-X approximately as long as broad. Maxillary palpi with palpomere III strongly swollen, approximately twice as long as broad, and palpomere IV minute and of conical shape.

Pronotum (Fig. 2) 1.13-1.14 times as long as broad and 1.19-1.24 times as broad as head, strongly convex in cross-section, broadest behind middle; lateral margins distinctly convex in dorsal view; punctation similar to that of head; interstices with shallow microreticulation; impunctate median band narrow.

Elytra (Fig. 2) 1.10-1.13 times as long as pronotum; punctation dense, moderately coarse, and moderately defined; interstices narrower than diameter of punctures, without 

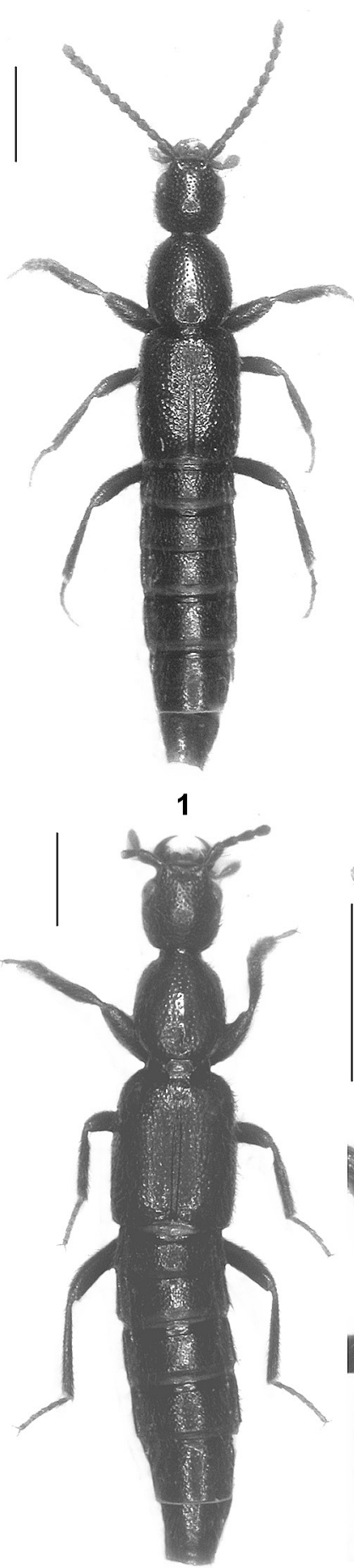

7

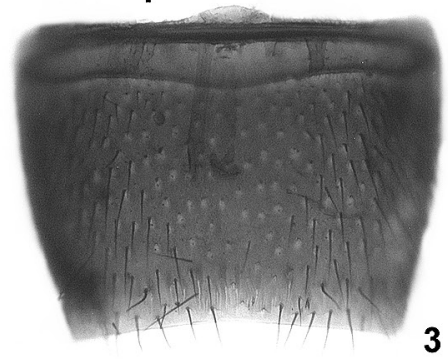

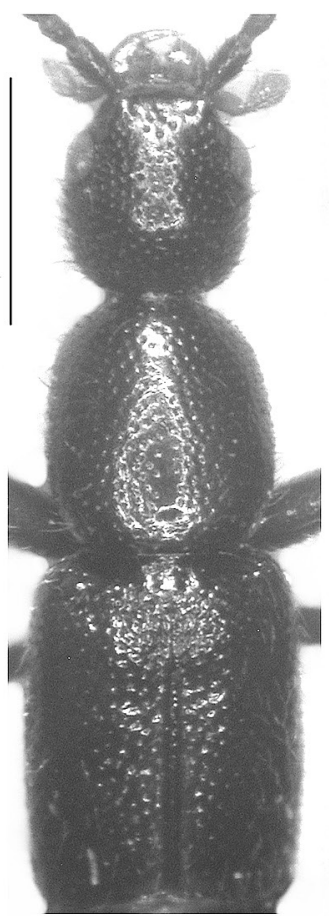

2

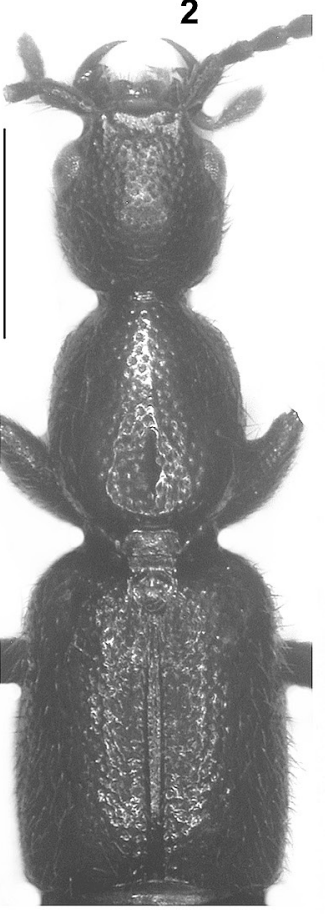

8

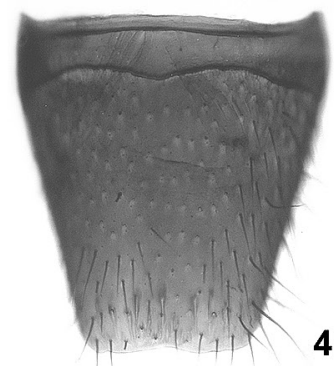

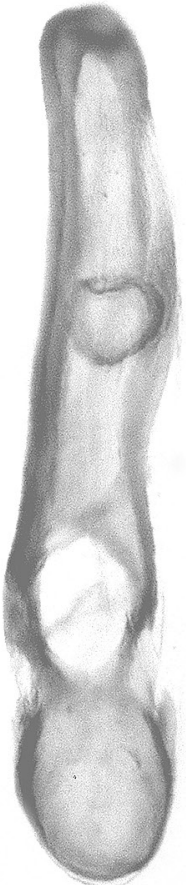

6

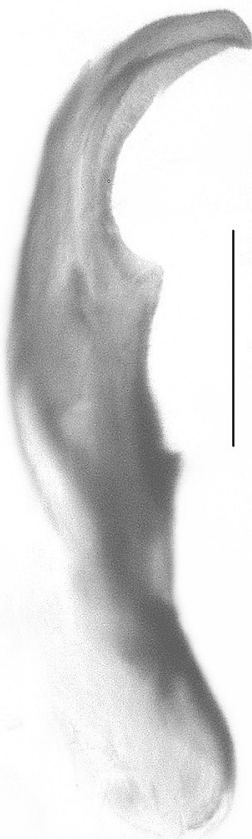

12
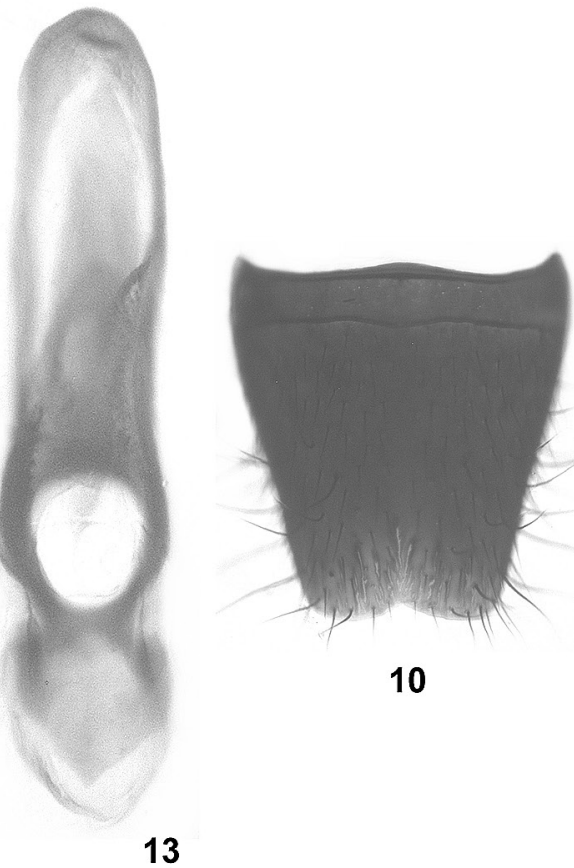

10

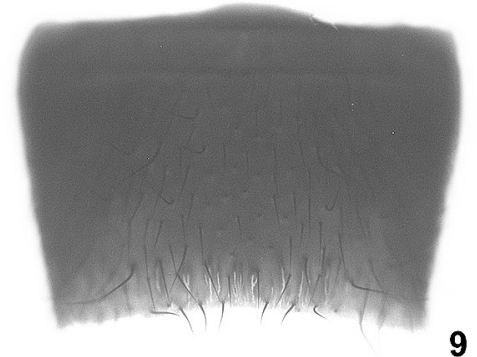

Figs 1-13: Elytrobium monilicorne (Sharp) (lectotype) (1-6) and E. gongganum sp. n. (7-13): habitus (1, 7); forebody (2, 8); male sternite VII $(3,9)$; male sternite VIII $(4,10)$; aedeagus in lateral and in ventral view $(5-6,12-13)$; male sternite IX (11). Scale bars: 1-2, 7-8: $1.0 \mathrm{~mm}$; 3-4, 9-10: 0.5 mm; 5-6, 11-13: $0.2 \mathrm{~mm}$. 
microreticulation; supramarginal line absent. Hind wings fully developed. Protarsomeres I-IV strongly dilated. Metatarsomere I approximately as long as II.

Abdomen narrower than elytra, segments III-VI of subequal width; punctation dense and distinct on anterior tergites, gradually becoming finer and sparser towards the abdominal apex; interstices with distinct microreticulation; posterior margin of tergite VII with palisade fringe.

$0^{\star}$ : postero-lateral processes of tergite IX apically spineshaped; sternite VII (Fig. 3) moderately transverse and with weakly concave posterior margin, pubescence unmodified; sternite VIII (Fig. 4) approximately as long as broad, shallowly impressed in the middle, posterior margin weakly concave in the middle, pubescence unmodified; aedeagus (Figs 5-6) $0.72 \mathrm{~mm}$ long, distinctly asymmetric, and without sclerotized internal structures.

\section{Comparative notes:}

Elytrobium monilicorne is the sole representative of the genus known from Japan. It is characterized by relatively large size, the conspicuously swollen maxillary palpomere III, and particularly by the shape of the aedeagus.

\section{Distribution and natural history:}

At present, the only confirmed record is from the Fujisan in Honshu, Japan (Map 1). The species was doubtfully reported also from Kamchatka (NAOMI et al. 2000) and
China (Jilin) (see PENG et al. 2012), but these records most likely refer to other species of Elytrobium and clearly require confirmation. Bionomic data are not available.

\section{Elytrobium gongganum sp. n.}

(Figs 7-13, Map 1)

\section{Type material:}

Holotype ơ: "CHINA, Sichuan, Gongga Shan, Lake abv. Camp 2, 2750 m, 25.7.1994, A. Smetana [C23] / Holotypus ơ Elytrobium gongganum sp. n., det. V. Assing 2013” (cAss).

\section{Etymology:}

The specific epithet is an adjective derived from the name of the mountain where this species was discovered.

\section{Description:}

Body length $7.8 \mathrm{~mm}$; length of forebody $4.0 \mathrm{~mm}$. Habitus as in Fig. 7. Coloration: body black; legs black with reddish tarsi; antennae with basal half blackish, apical half gradually becoming paler towards apex.

Head (Fig. 8) 1.05 times as long as broad, broadest across eyes, and weakly tapering behind eyes; posterior angles broadly rounded, indistinct; frons transversely impressed and with pronounced microsculpture; punc-

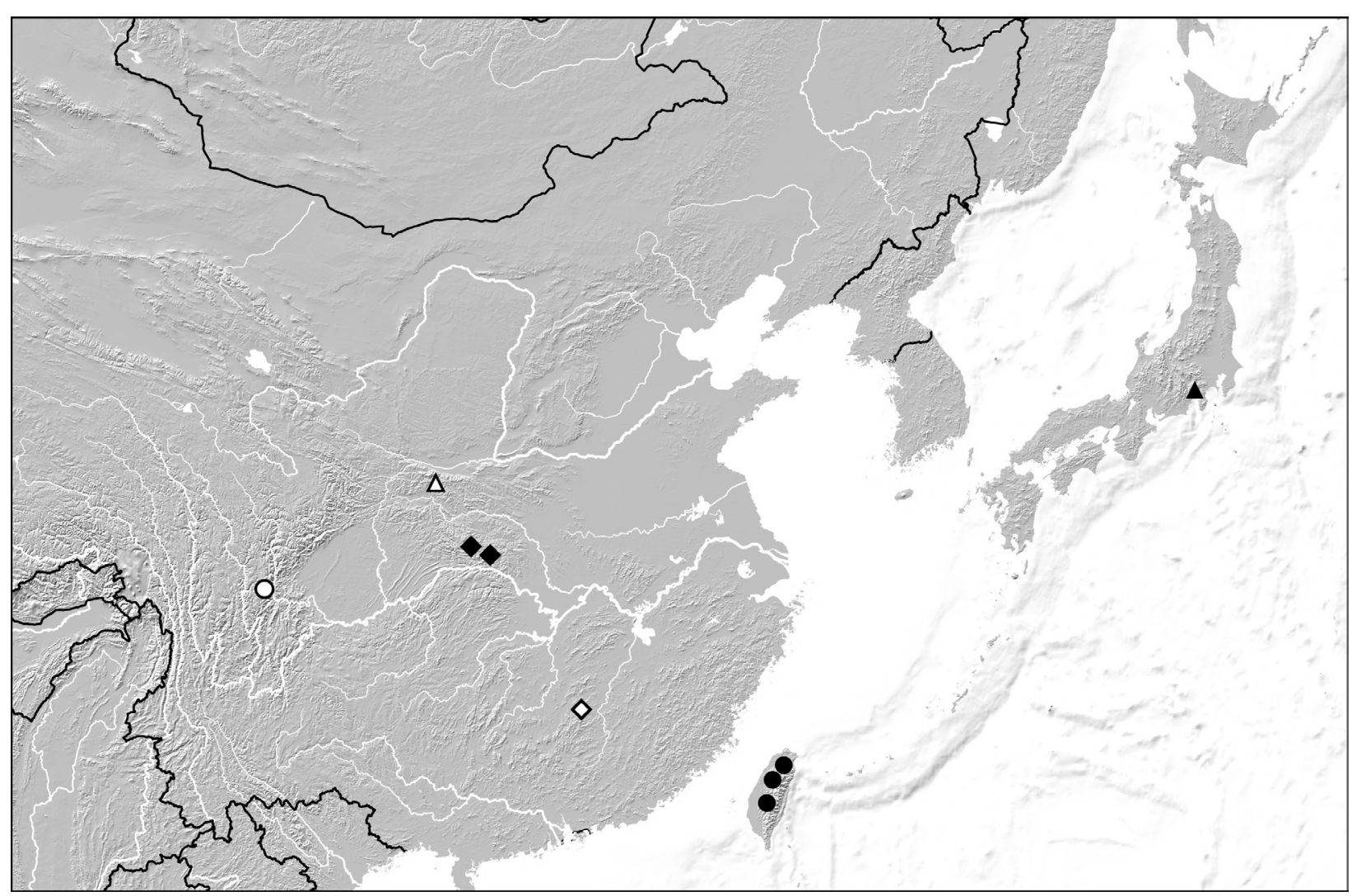

Map 1: Distribution of Elytrobium gen.n. in the southeastern East Palaearctic region: E. gongganum sp. n. (open circle); E. qinlinganum sp. n. (open triangle); E. scindens sp. n. (filled diamonds); E. seminitidum sp. n. (open diamond); E. alesianum sp. n. (filled circles); E. monilicorne (SHARP) (filled triangle). 
tation coarse and dense, slightly sparser in median dorsal portion; interstices narrower than diameter of punctures (except in median dorsal portion), with distinct microreticulation, and subdued shine. Eyes moderately large and composed of numerous fine ommatidia, approximately 0.6 times as long as postocular region from posterior margin of eye to neck in dorsal view. Antenna $2.0 \mathrm{~mm}$ long; antennomeres IV-X weakly oblong. Maxillary palpomere III slender, approximately 3.5 times as long as broad.

Pronotum (Fig. 8) 1.16 times as long as broad and 1.15 times as broad as head, strongly convex in crosssection, broadest slightly behind middle; lateral margins distinctly convex in dorsal view; punctation similar to that of head; interstices with very shallow, nearly obsolete microreticulation; impunctate median band narrow.

Elytra (Fig. 8) 1.15 times as long as pronotum; punctation dense, fine, and indistinctly seriate; interstices without microreticulation. Hind wings fully developed. Protarsomeres I-IV strongly dilated. Metatarsomere I approximately as long as II.

Abdomen distinctly narrower than elytra, segments III-VI of subequal width; punctation dense and distinct on anterior tergites, gradually becoming finer and sparser towards the abdominal apex; interstices with distinct microreticulation; posterior margin of tergite VII with palisade fringe.

$0^{*}$ : sternite VII (Fig. 9) moderately transverse and with weakly concave posterior margin, pubescence unmodified; sternite VIII (Fig. 10) weakly oblong, posterior excision very shallow, but with noticeable angle in the middle, pubescence unmodified; sternite IX nearly symmetric and apically with long and acute process (Fig. 11); aedeagus $0.75 \mathrm{~mm}$ long, shaped as in Figs 12-13.

\section{Comparative notes:}

Elytrobium gongganum is distinguished from E. monilicorne by larger body size, the more slender antennae with oblong antennomeres IV-X, the much more slender maxillary palpomere III, the much finer and indistinctly seriate punctation of the elytra, the differently shaped male sternite VIII, as well as by the shape of the aedeagus.

\section{Distribution and natural history:}

The type locality is situated in the Gongga Shan, a mountain in western Sichuan (Map 1). The holotype was sifted from wet moss and grassy vegetation on large fallen trees in a swampy habitat around a shallow forest pond at an altitude of $2750 \mathrm{~m}$ (SMETANA pers. comm.).
Elytrobium qinlinganum sp. $\mathrm{n}$.

(Figs 14-21, Map 1)

Type material:

Holotype ơ: "CHINA (S-Shaanxi) Qinling Shan, pass on rd. Zhouzhi-Foping, 105 km SW Xi’an, N-slope, $1990 \mathrm{~m}$, $33^{\circ} 44^{\prime} \mathrm{N}, 107^{\circ} 59^{\prime} \mathrm{E}$ ( small creek vall., mix. decid. for., bamboo, small meadows) 2.\&4.VII.2001 Wrase [01] / Holotypus ơ Elytrobium qinlinganum sp. n., det. V. Assing 2013” (cAss).

\section{Etymology:}

The specific epithet is an adjective derived from the name of the mountain range where this species was discovered.

\section{Description:}

Body length $6.8 \mathrm{~mm}$; length of forebody $3.8 \mathrm{~mm}$. Habitus as in Fig. 14. Coloration: body black; legs blackish-brown with reddish tarsi; antennae reddish-brown with slightly darker antennomere I.

Head (Fig. 15) 1.05 times as long as broad, broadest across eyes, and distinctly tapering behind eyes; posterior angles broadly rounded, indistinct; punctation coarse and dense, slightly sparser in median dorsal portion; interstices narrower than diameter of punctures (except in median dorsal portion), with distinct microreticulation, and subdued shine. Eyes moderately large and composed of numerous fine ommatidia, approximately half as long as postocular region from posterior margin of eye to neck in dorsal view. Antenna (Fig. 16) $1.9 \mathrm{~mm}$ long; antennomeres IV-X barely noticeably oblong. Maxillary palpi with palpomere III moderately slender, approximately 3 times as long as broad.

Pronotum (Fig. 15) rather slender, 1.2 times as long as broad and 1.08 times as broad as head, moderately convex in cross-section, broadest slightly behind middle; lateral margins nearly straight in dorsal view; punctation slightly coarser and sparser than that of head; interstices glossy, without microreticulation; impunctate median band narrow.

Elytra (Fig. 15) very long and large, 1.18 times as long as pronotum; punctation dense, distinct, as coarse as that of pronotum, and indistinctly seriate; interstices without microreticulation, glossy. Hind wings fully developed. Protarsomeres I-IV strongly dilated. Metatarsomere I approximately as long as II.

Abdomen distinctly narrower than elytra, segments III-VI of subequal width; punctation dense and rather coarse on anterior tergites, gradually becoming finer and sparser towards the abdominal apex; interstices with distinct microreticulation; posterior margin of tergite VII with palisade fringe. 


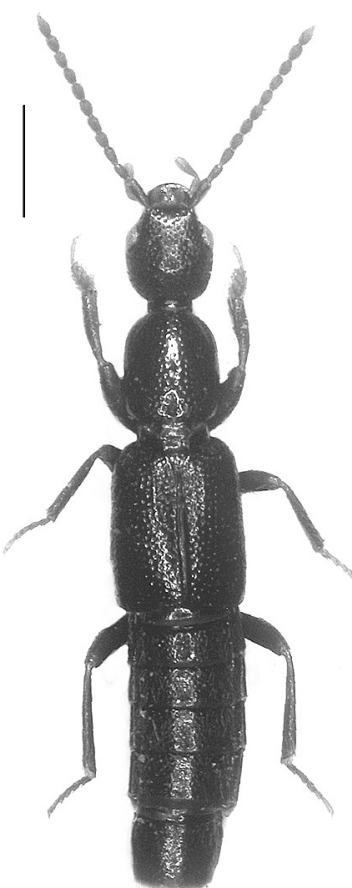

14

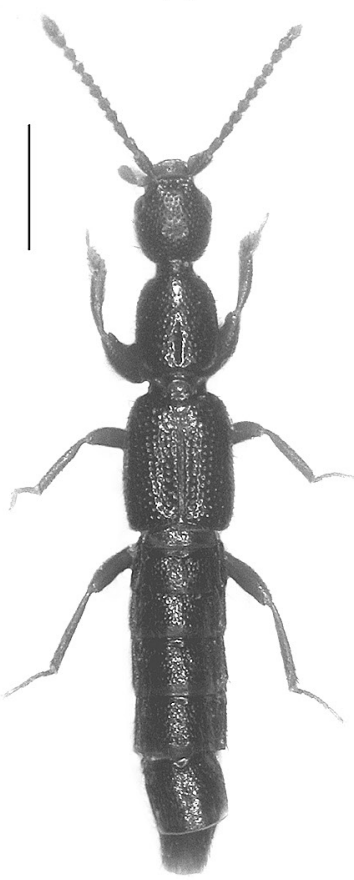

22

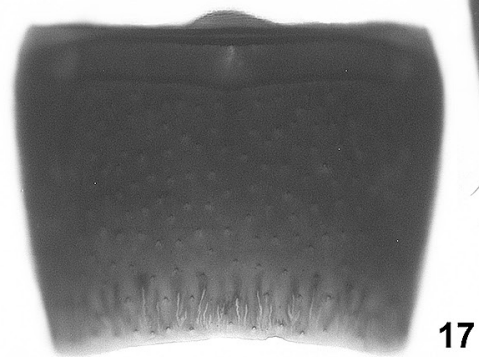

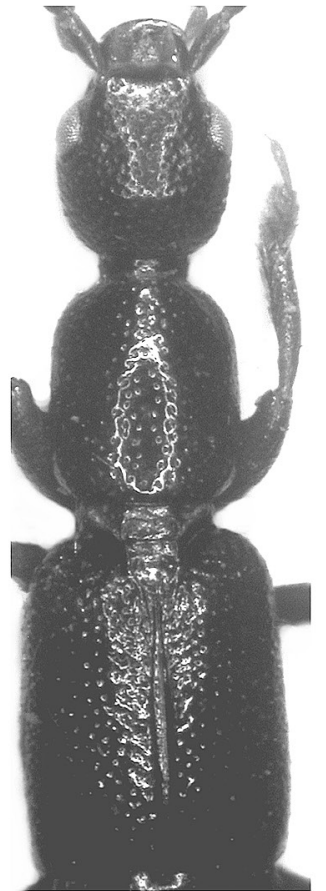

15

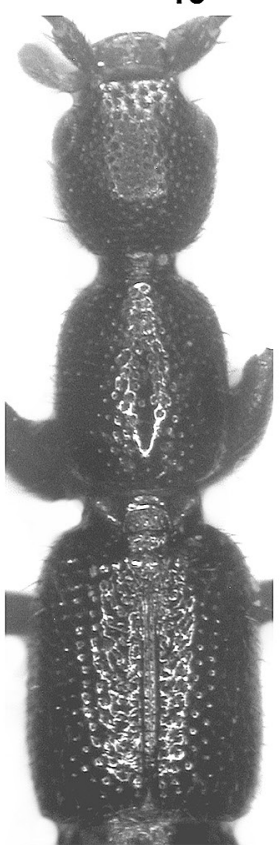

23

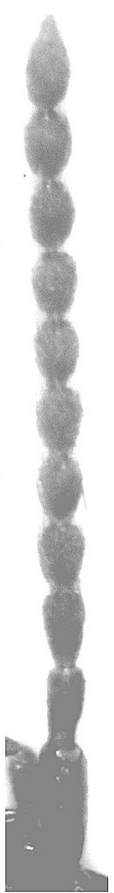

16

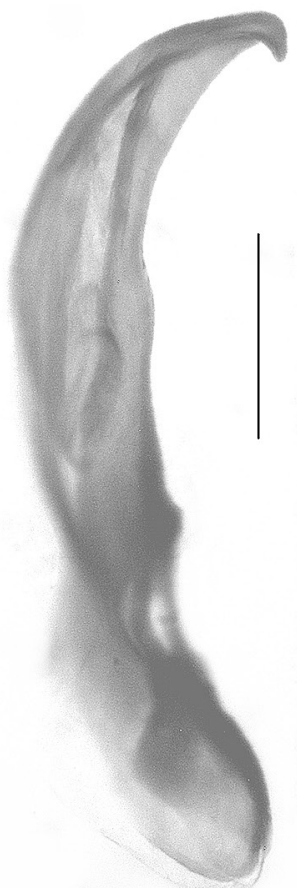

20

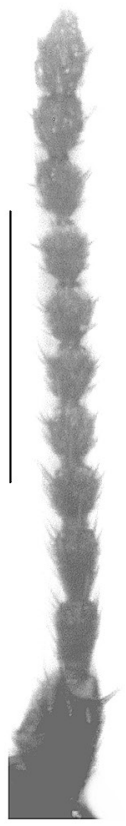

24
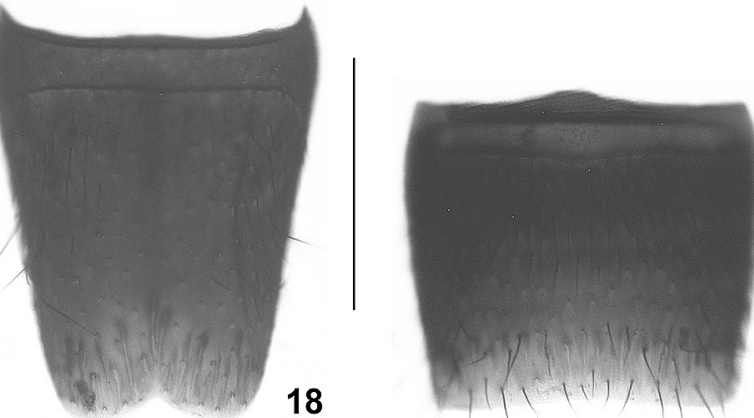
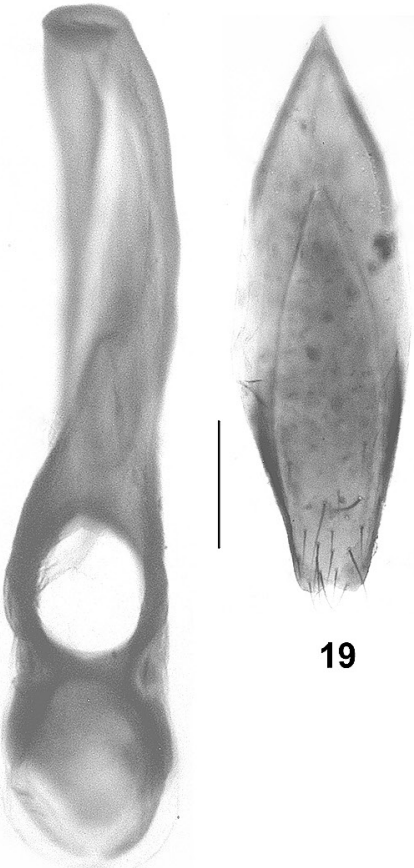

19
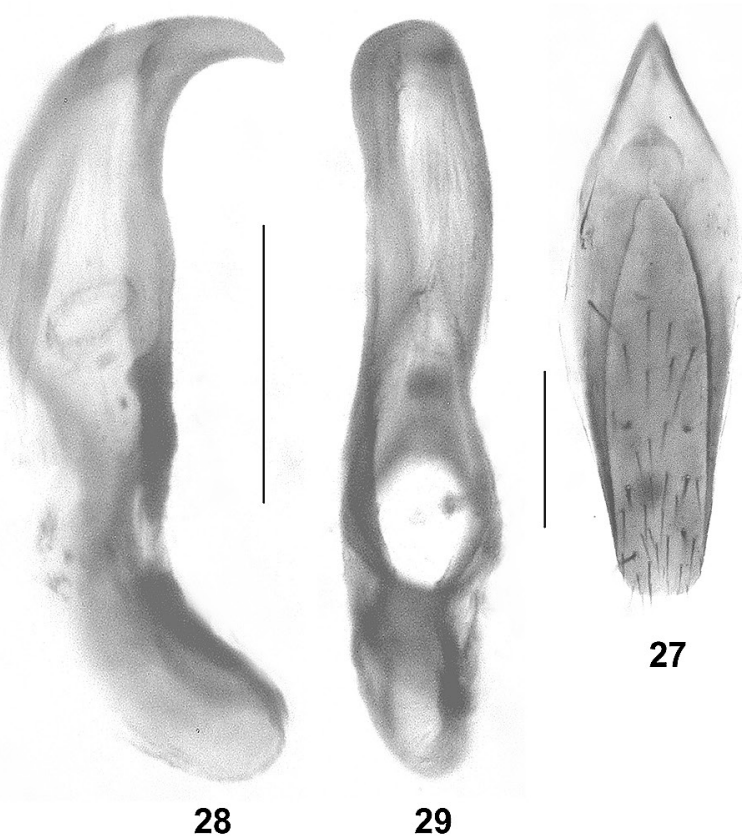

27

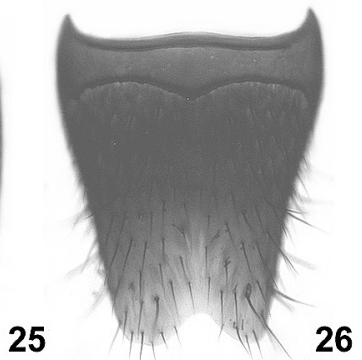

Figs 14-29: Elytrobium qinlinganum sp. n. (14-21) and E. seminitidum sp. n. (22-29): habitus (14, 22); forebody (15, 23); antenna $(16,24)$; male sternite VII $(17,25)$; male sternite VIII $(18,26)$; male sternite IX $(19,27)$; aedeagus in lateral and in ventral view (20-21, 28-29). Scale bars: 14-15, 22-23: $1.0 \mathrm{~mm}$; 16-18, 24-26: $0.5 \mathrm{~mm}$; 19-21, 27-29: $0.2 \mathrm{~mm}$. 
$\sigma^{*}$ : sternite VII (Fig. 17) moderately transverse and with very weakly concave posterior margin, pubescence unmodified; sternite VIII (Fig. 18) distinctly oblong, nearly 1.2 times as long as broad, posterior excision shallow and with noticeable angle in the middle, pubescence unmodified; sternite IX (Fig. 19) symmetric and apically acute; aedeagus larger than in other species of the genus, nearly $0.9 \mathrm{~mm}$ long, shaped as in Figs 20-21.

\section{Comparative notes:}

From the other species of similar size, E. gongganum and E. monilicorne, E. qinlinganum is distinguished by the more slender pronotum with straight lateral margins, the absence of microsculpture on the pronotum, the relatively longer and larger elytra, the distinctly oblong male sternite VIII, and the larger and differently shaped aedeagus. It additionally differs from E. gongganum by the different coloration of the antennae and the more glossy and much more coarsely punctate elytra, and from E. monilicorne by somewhat larger size, more slender maxillary palpomeres III, more slender antennae, and the angled posterior excision of the male sternite VIII.

\section{Distribution and natural history:}

The type locality is situated in the Qinling Shan in southern Shaanxi (Map 1). The holotype was collected in a stream valley with mixed deciduous forest and bamboo at an altitude of $1990 \mathrm{~m}$.

\section{Elytrobium seminitidum sp. n.} (Figs 22-29, Map 1)

\section{Type material:}

Holotype ơ: "CHINA, Jiangxi prov., 27.iv.2011, Jinggang Shan Mts., SONGMUPING (stream valley), $26^{\circ} 34.7^{\prime} \mathrm{N}$, $114^{\circ} 04.3^{\prime} \mathrm{E}, 1280$ m, M. Fikáček \& J. Hájek leg. / Holotypus ơ Elytrobium seminitidum sp. n., det. V. Assing 2013" (NMP).

\section{Etymology:}

The specific epithet (Latin, adjective: half-shiny) alludes to the glossy pronotum and elytra distinctly contrasting with the matt head.

\section{Description:}

Small species; body length $6.0 \mathrm{~mm}$; length of forebody $3.0 \mathrm{~mm}$. Habitus as in Fig. 22. Coloration: body black; legs reddish-brown with reddish tarsi and infuscate profemora; antennae reddish with slightly darker antennomere I.

Head (Fig. 23) 1.08 times as long as broad, broadest across eyes, and distinctly tapering behind eyes; posterior angles broadly rounded, indistinct; punctation coarse and dense, sparser in median dorsal portion; interstices nar- rower than diameter of punctures (except in median dorsal portion), with very distinct microreticulation, nearly matt. Eyes moderately large and composed of numerous fine ommatidia, approximately half as long as postocular region from posterior margin of eye to neck in dorsal view. Antenna (Fig. 24) $1.5 \mathrm{~mm}$ long; antennomeres IV-X approximately as long as broad. Maxillary palpi with palpomere III moderately dilated, approximately 2.5 times as long as broad.

Pronotum (Fig. 23) rather slender, 1.2 times as long as broad and 1.06 times as broad as head, distinctly convex in cross-section, broadest slightly behind middle; lateral margins weakly convex in dorsal view; punctation similar to that of head; interstices glossy, without microreticulation; impunctate median band confined to posterior half.

Elytra (Fig. 23) moderately long, 1.03 times as long as pronotum; punctation dense, as coarse as that of pronotum, defined, and indistinctly seriate; interstices without microreticulation, glossy. Hind wings fully developed. Protarsomeres I-IV strongly dilated. Metatarsomere I approximately as long as II.

Abdomen narrower than elytra, segments III-VI of subequal width; punctation very dense and coarse on anterior tergites, gradually becoming finer and sparser towards the abdominal apex; interstices on tergites III-VI with indistinct microreticulation and glossy, on tergites VII-VIII with slightly more distinct microsculpture; posterior margin of tergite VII with palisade fringe.

$0^{7}$ : sternite VII (Fig. 25) weakly transverse, approximately 1.15 times as broad as long, and with very weakly concave posterior margin, pubescence unmodified; sternite VIII (Fig. 26) 1.08 times as long as broad, posterior excision deeper than in other species of the genus; pubescence unmodified; sternite IX (Fig. 27) symmetric and apically acute; aedeagus $0.54 \mathrm{~mm}$ long, ventral process abruptly bent subapically (Figs 28-29).

\section{Comparative notes:}

Elytrobium seminitidum is characterized particularly by the glossy pronotum, elytra, and abdomen distinctly contrasting with the matt head, by the relatively short elytra, by the weakly transverse sternite VII, by the deeper posterior excision of the male sternite VIII, and by the shape of the aedeagus. It additionally differs from the preceding species by smaller body size.

\section{Distribution and natural history:}

The type locality is situated in the Jinggang Shan, Jiangxi province, southeastern China (Map 1), at an altitude of $1280 \mathrm{~m}$. 
Elytrobium scindens sp. $\mathrm{n}$.

(Figs 30-42, Map 1)

Type material:

Holotype o: "CHINA: border Shaanxi-Sichuan [today border Shaanxi-Chongqing], Daba Shan, pass $20 \mathrm{~km}$ SSE Zhenping / 1700-1800 m, 31 $44^{\circ} \mathrm{N}, 109^{\circ} 35^{\prime} \mathrm{E}, 9$. VII.2001 A. Smetana [C96a] / Holotypus ơ Elytrobium scindens sp. n., det. V. Assing 2013" (cAss). Paratype $9:$ "CHINA (W-Hubei) Daba Shan, pass E Mt. Da Shennongjia, $12 \mathrm{~km}$ NW Muyuping, $31^{\circ} 30^{\prime} \mathrm{N}, 110^{\circ} 21^{\prime} \mathrm{E}, 1950 \mathrm{~m}$ (dry creek vall., mix. decid. forest) 16.-22.VII.2001 Wrase [13]" (cSch).

\section{Etymology:}

The specific epithet is the present participle of the Latin verb scindere (to scratch) and refers to the distinctly hook-shaped apex of the ventral process of the aedeagus.

\section{Description:}

Small species; body length $5.5-6.5 \mathrm{~mm}$; length of forebody $3.0-3.1 \mathrm{~mm}$. Habitus as in Fig. 30. Coloration: head blackish; pronotum blackish-brown; elytra and abdomen dark brown; legs with the femora dark-brown, the tibiae reddish-brown, and the tarsi yellowish-brown; antennae yellowish-red, with antennomere I slightly darker.

Head (Fig. 31) 1.10-1.13 times as long as broad, broadest at posterior margin of eyes; lateral margins not converging directly behind eyes, but smoothly curving towards neck in dorsal view; posterior angles indistinct; frons transversely impressed and with pronounced microsculpture; punctation coarse and dense, sparser in median dorsal portion; interstices narrower than diameter of punctures (except in median dorsal portion), with very distinct microreticulation and subdued shine. Ventral aspect of head as in Fig. 32. Eyes moderately large and composed of numerous fine ommatidia, approximately half as long as postocular region from posterior margin of eye to neck in dorsal view. Antenna $1.4 \mathrm{~mm}$ long; antennomeres IV-X approximately as long as broad. Maxillary palpi with palpomere III distinctly dilated apicad, somewhat flattened (i.e., oval in cross-section), approximately 2.5 times as long as broad. Other mouthparts as in Figs 40-42.

Pronotum (Fig. 31) 1.20-1.23 times as long as broad and 1.12-1.13 times as broad as head, moderately convex in cross-section, broadest slightly behind middle; lateral margins weakly convex in dorsal view, nearly straight; punctation similar to that of head; interstices with distinct microreticulation; impunctate median band very narrow.
Elytra (Fig. 31) moderately long, approximately as long as pronotum; punctation dense, as coarse as that of pronotum, weakly defined to defined, irregular, not seriate; interstices without microreticulation, glossy. Hind wings fully developed. Protarsomeres I-IV strongly dilated. Metatarsomere I approximately as long as II.

Abdomen slightly narrower than elytra, segments III-VI of subequal width; punctation not very dense and moderately coarse on anterior tergites, gradually becoming finer and sparser towards the abdominal apex; interstices with shallow microreticulation; posterior margin of tergite VII with palisade fringe.

$0^{\top}$ : sternite VII (Fig. 33) distinctly transverse, 1.45 times as broad as long, and with very weakly concave posterior margin, pubescence unmodified; sternite VIII (Fig. 34) weakly oblong, posterior excision very shallow and not angled in the middle, pubescence unmodified; sternite IX symmetric and apically moderately acute (Fig. 35); aedeagus (Figs 36-37) $0.65 \mathrm{~mm}$ long, ventral process abruptly bent subapically and apically distinctly hooked in lateral view.

\%: sternite VIII (Fig. 38) 1.1 times as long as broad and with distinctly convex posterior margin; tergites IX-X as in Fig. 39.

\section{Comparative notes:}

Elytrobium scindens differs from the similarly small E. seminitidum particularly by the presence of microsculpture on the pronotum, the transversely impressed frons, the slightly shorter elytra with non-seriate punctation, the less coarse and less dense punctation of the abdomen, the much more transverse male sternite VII, the much shallower posterior excision of the male sternite VIII, and by the differently shaped aedeagus. From the other species (re-)described above it is readily distinguished by smaller body size alone.

\section{Distribution and natural history:}

The species is known from two localities in the Daba Shan, one at the border between Chongqing and southern Shaanxi, and one in western Hubei (Map 1). The holotype was sifted from moist to wet moss, fallen leaves and other debris around a small seepage in a secondary deciduous forest (SMETANA pers. comm.), the paratype was collected in a mixed deciduous forest. The altitudes range from approximately 1750 to $1950 \mathrm{~m}$. 


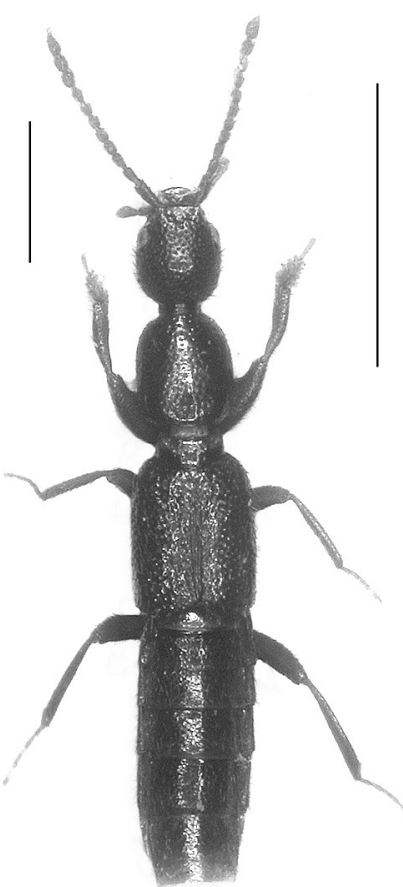

30

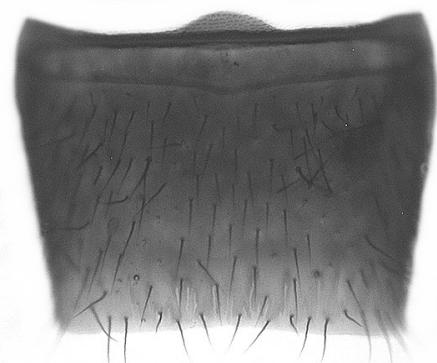

33

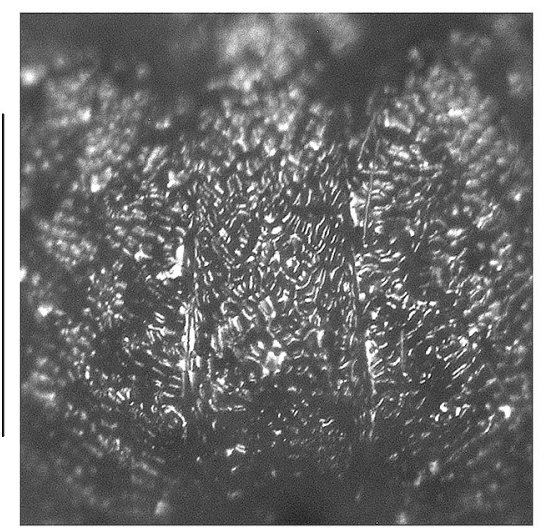

32

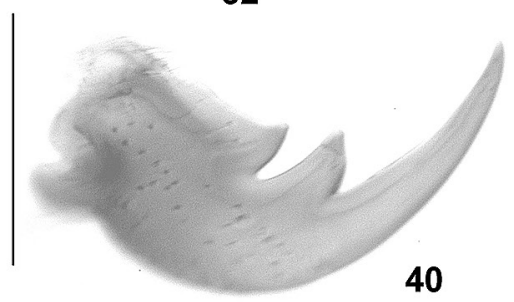

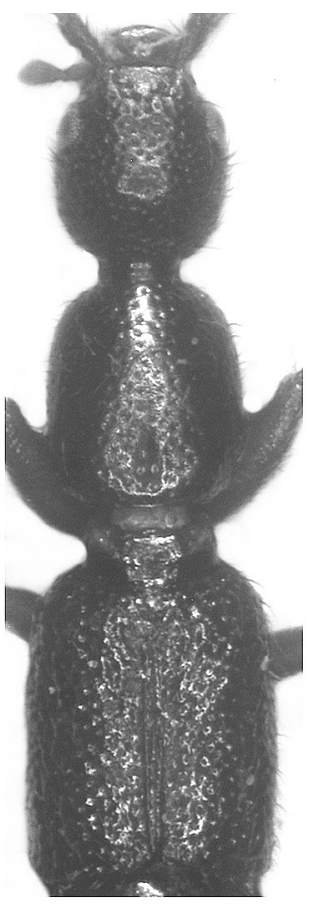

31

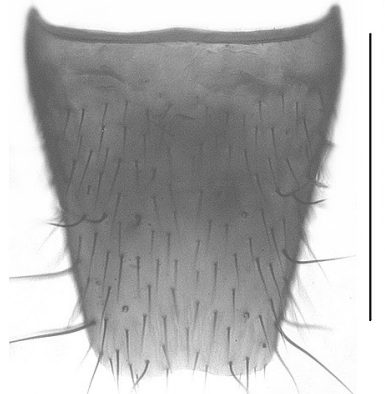

34
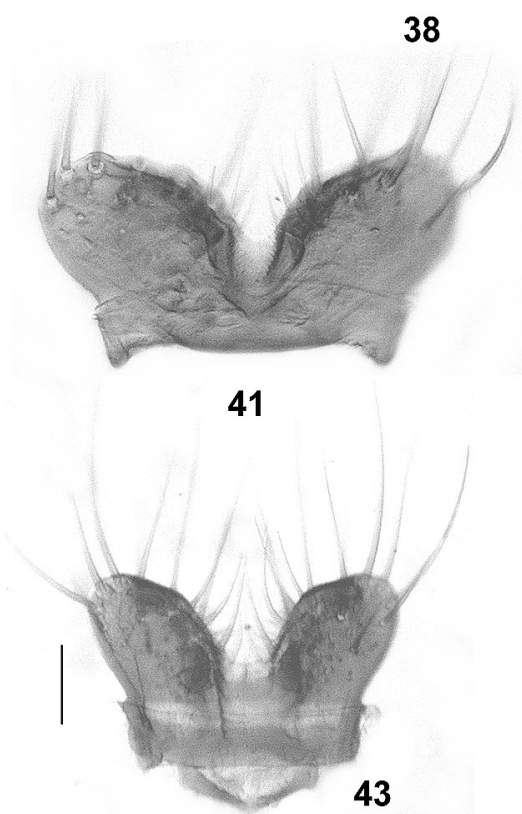

36

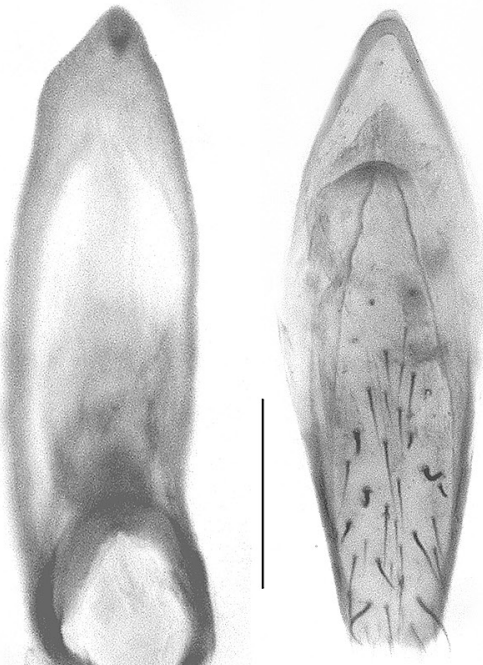

35

37

41
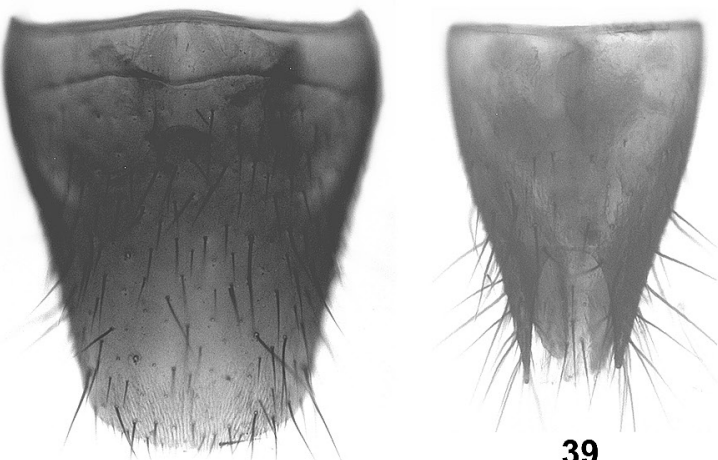

39

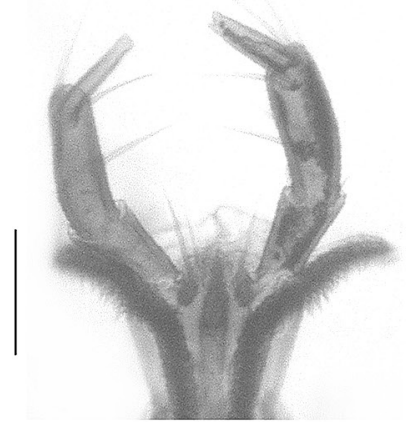

44

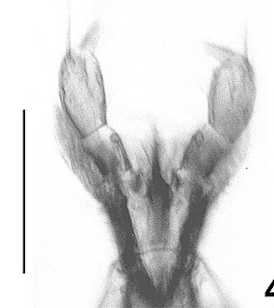

Figs 30-44: Elytrobium scindens sp. n. (30-42) and Lathrobium elongatum (LinNAEus) (43-44): habitus (30); forebody (31); median portion of ventral aspect of head (32); male sternite VII (33); male sternite VIII (34); male sternite IX (35); aedeagus in lateral and in ventral view (36-37); female sternite VIII (38); female tergites IX-X (39); right mandible (40); labrum (41, 43); labium (42, 44). Scale bars: 30-31: $1.0 \mathrm{~mm}$; 33-34, 38-39: 0.5 mm; 32, 35-37, 40: 0.2 mm; 41-44: $0.1 \mathrm{~mm}$. 
Elytrobium alesianum sp. $\mathrm{n}$.

(Figs 45-57, Map 1)

\section{Type material:}

Holotype 0": "TAIWAN Chiai Hsien, Alishan, Sister Ponds 2180 m, 26.IV.1990, A. Smetana [T24] / Holotypus $0^{\top}$ Elytrobium alesianum sp. n., det. V. Assing 2013" (cAss). Paratypes: $10^{\text {t': }}$ "TAIWAN Taoyuan Hsien, Taku- anshan For. 17.IV.90 1600 m, A. Smetana [T3]" (cAss); 1 \%: "TAIWAN, Taichung Hsien, Anmashan, 2225 m, 11-15.V.92, A. Smetana [T122]" (cSme).

\section{Etymology:}

It is with great pleasure that I dedicate this species to Aleš Smetana (Ottawa), one of the foremost staphylinidologists of all times, whose outstanding material from

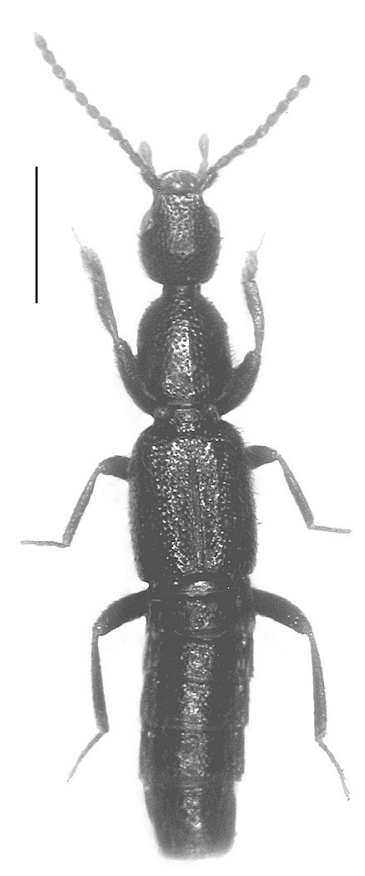

45

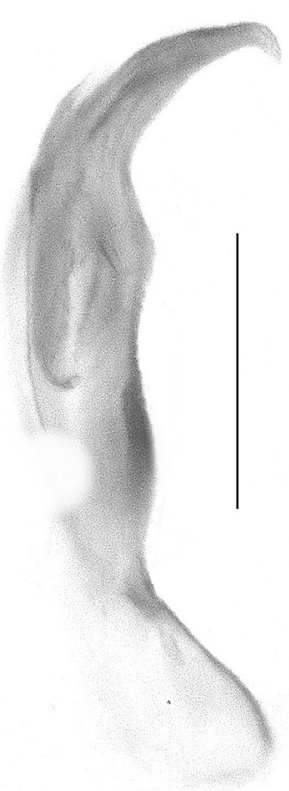

54

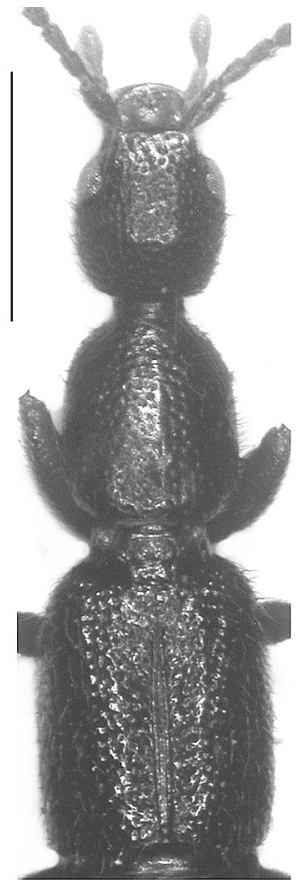

46

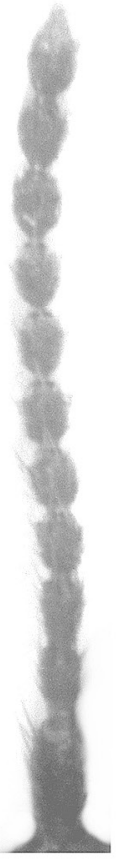

47

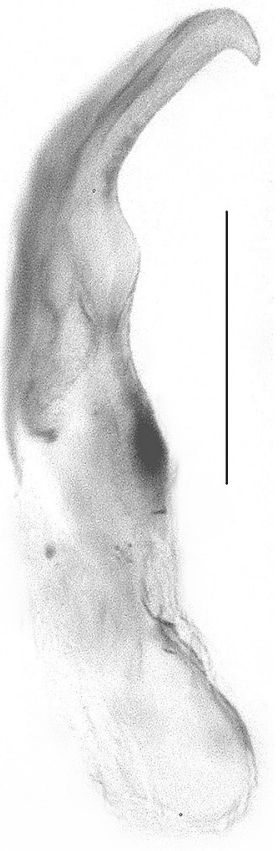

51

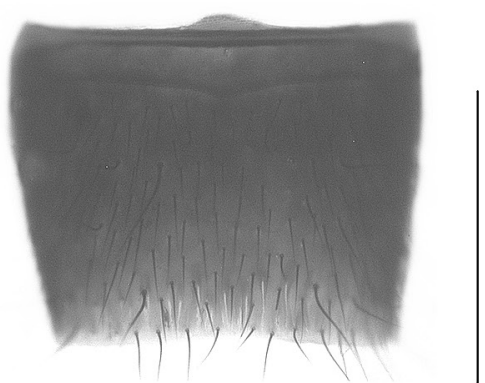

48

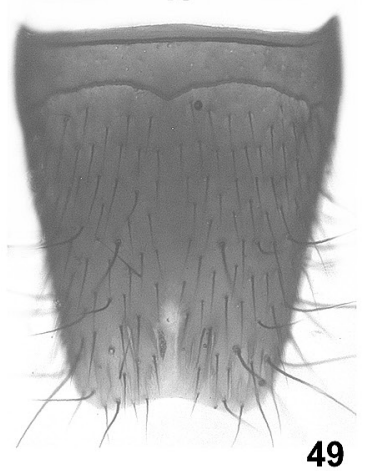

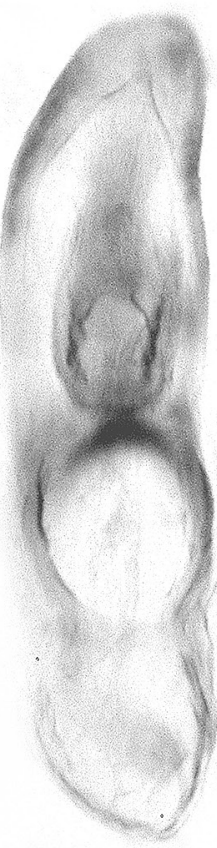

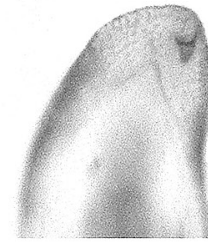

53

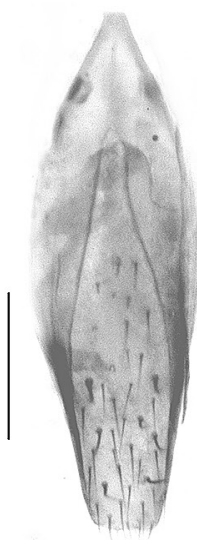

52

50
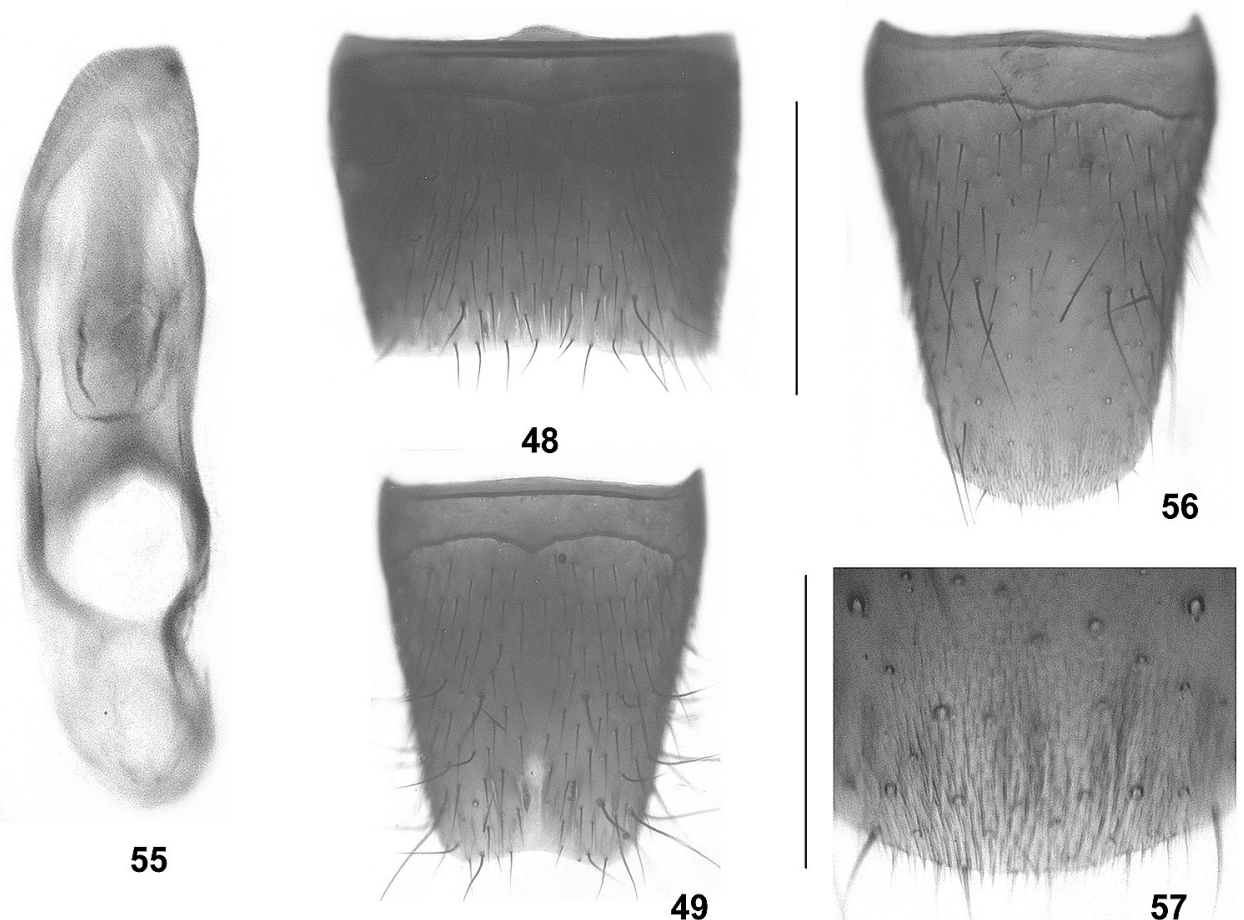

Figs 45-57: Elytrobium alesianum sp. n. (45-53: holotype): habitus (45); forebody (46); antenna (47); male sternite VII (48); male sternite VIII (49); male sternite IX (50); aedeagus in lateral and in ventral view (51-52, 54-55); apical portion of ventral process of aedeagus in ventral view (53); female sternite VIII (56); postero-median portion of female sternite VIII (57). Scale bars: 45-46: $1.0 \mathrm{~mm} ; 47-49,56: 0.5 \mathrm{~mm}$; 50-55, 57: $0.2 \mathrm{~mm}$. 
Taiwan has so significantly contributed to the knowledge of the staphylinid fauna of this island and who collected the majority of the type specimens studied in the present paper.

\section{Description:}

Small species; body length 5.0-5.8 mm; length of forebody 2.0-3.2 mm. Habitus as in Fig. 45. Coloration: body black; legs with the femora blackish-brown, the tibiae dark-brown, and the tarsi yellowish-brown; antennae dark-yellowish, with antennomere I darker; maxillary palpi yellowish.

Head (Fig. 46) 1.12-1.15 times as long as broad, broadest across eyes or at posterior margin of eyes, tapering behind eyes; lateral margins smoothly curving towards neck in dorsal view; posterior angles indistinct; frons transversely impressed and with pronounced microsculpture; punctation coarse and dense, sparser in median dorsal portion; interstices narrower than diameter of punctures (except in median dorsal portion), with very distinct microreticulation and subdued shine. Eyes mod- erately large and composed of numerous fine ommatidia, approximately half as long as postocular region from posterior margin of eye to neck in dorsal view. Antenna (Fig. 47) 1.5-1.6 mm long; antennomeres IV-X approximately as long as broad. Maxillary palpi with palpomere III distinctly dilated apicad, barely 2.5 times as long as broad.

Pronotum (Fig. 46) approximately 1.2 times as long as broad and 1.15-1.17 times as broad as head, moderately convex in cross-section, broadest slightly behind middle; lateral margins weakly convex in dorsal view, nearly straight; punctation similar to that of head; interstices with distinct microreticulation; impunctate median band very narrow and short, reaching neither anterior nor posterior margins.

Elytra (Fig. 46) long, 1.07-1.09 times as long as pronotum; punctation dense, as coarse as that of pronotum, defined, irregular, not seriate; interstices without microreticulation, glossy. Hind wings fully developed. Protarsomeres

\section{Key to the species of Elytrobium}

1. Larger species, length of forebody at least $3.4 \mathrm{~mm}$. Species from China and Japan.

Smaller species, length of forebody $3.2 \mathrm{~mm}$ at most. Species from China and Taiwan.

2. Maxillary palpomere III strongly dilated, little more than twice as long as broad. Male sternite VIII posteriorly very shallowly concave (Fig. 4). Aedeagus as in Figs 5-6. Japan. monilicorne (SHARP)

Maxillary palpomere III slender, approximately 3.5 times as long as broad. Male sternite VIII more distinctly excised posteriorly. Aedeagus of different shape. China.

3. Pronotum without trace of microsculpture (Fig. 15). Elytra, distinctly glossy; punctation defined and as coarse as that of pronotum (Fig. 15). Antennomeres II-XI reddish. Male sternite VIII more distinctly oblong (Fig. 17). Aedeagus approximately $0.9 \mathrm{~mm}$ long, larger than in other species of the genus, and shaped as in Figs 20-21. Qinling Shan. qinlinganum sp. $\mathrm{n}$.

Pronotum, except for the impunctate median band, with shallow microsculpture (Fig. 8). Elytral punctation less defined and finer than that of pronotum; interstices less glossy (Fig. 8). Antennomeres II-VI dark-brown. Male sternite VIII weakly oblong (Fig. 4). Aedeagus smaller, $0.75 \mathrm{~mm}$ long and shaped as in Figs 12-13. Gongga Shan.

gongganum sp. $\mathrm{n}$.

4. Pronotum without microsculpture (Fig. 23). Male sternite VII weakly transverse (Fig. 25). Posterior excision of male sternite VIII relatively deep (Fig. 26). Aedeagus with ventral process apically acute, not hooked (Figs 28-29). China: Jiangxi: Jinggang Shan. seminitidum sp. $\mathrm{n}$

Pronotum with distinct microreticulation (Figs 31, 46). Male sternite VII more strongly transverse (Figs 33, 48). Posterior excision of male sternite VIII shallow (Figs 34, 49). Ventral process of aedeagus apically hooked (Figs 36, $51,54)$.

5. Head with lateral margins smoothly curving towards neck, not tapering immediately behind eyes. Elytra shorter, approximately as long as pronotum (Fig. 31). Male sternite VII more strongly transverse, 1.45 times as broad as long (Fig. 33). Male sternite VIII weakly oblong (Fig. 34). Aedeagus slightly larger (0.65 mm) and shaped as in Figs 36-37. Female sternite VIII less oblong, 1.1 times as long as broad (Fig. 38). China: Daba Shan.

scindens sp. n.

Head tapering posteriad immediately behind eyes. Elytra longer, 1.07-1.09 times as long as pronotum (Fig. 46). Male sternite VII less transverse, 1.35 times as broad as long (Fig. 48). Male sternite VIII distinctly oblong (Fig. 49). Aedeagus 0.57-0.61 mm long and shaped as in Figs 51-55. Female sternite VIII more oblong, 1.3 times as long as broad (Fig. 56). Taiwan. alesianum sp. $\mathrm{n}$. 
I-IV strongly dilated in both sexes. Metatarsomere I approximately as long as II.

Abdomen distinctly narrower than elytra, segments III-VI of subequal width; punctation moderately dense and moderately coarse on anterior tergites, gradually becoming finer and sparser towards the abdominal apex; interstices with shallow microreticulation; posterior margin of tergite VII with palisade fringe.

$\sigma^{*}$ : sternite VII (Fig. 48) moderately transverse, approximately 1.35 times as broad as long, and with very weakly concave posterior margin, pubescence unmodified; sternite VIII (Fig. 49) distinctly oblong, posterior excision very shallow and not angled in the middle, pubescence unmodified; aedeagus $0.57-0.61 \mathrm{~mm}$ long, ventral process abruptly bent subapically and apically distinctly hooked in lateral view (Figs 51-55).

ㅇ: sternite VIII strongly oblong, approximately 1.3 times as long as broad and with distinctly convex posterior margin.

\section{Comment:}

The female from the Anmashan is only tentatively included in the type series. Its head is of slightly different shape (not tapering immediately behind eyes), the lateral margins of the pronotum are subparallel, the elytra are dark-brown, and the legs are paler than in the male specimens. These differences are interpreted as an expression of intraspecific variation until evidence suggesting otherwise becomes available. Nevertheless, except for the female sexual characters, the above description is exclusively based on the two males.

The aedeagus appears to be subject to some intraspecific variation, too. In the paratype from the Takuanshan, it is somewhat smaller and the ventral process is apically more slender than in the holotype (Figs 51-55).

\section{Comparative notes:}

Both in external and in sexual characters, E. alesianum is most similar to E. scindens, from which it is distinguished by the different head shape, the longer elytra, the slightly shorter and more strongly dilated maxillary palpomere III, the less transverse male sternite VII, the more oblong male sternite VIII, the slightly smaller and differently shaped aedeagus, and the more strongly oblong female sternite VIII.

\section{Distribution and natural history:}

The species was discovered in three localities in Taiwan (Map 1). The holotype was sifted from debris, leaf litter, and moss along a stream in an old, probably original mixed broadleaved and coniferous forest, the male paratype was collected in a mostly coniferous forest by dipping moss and vegetation along two small ponds into water, and the female paratype was found in a yellow pan trap in a primary mixed forest (SMETANA pers. comm.). The altitudes range from 1600 to $2225 \mathrm{~m}$.

\section{Sinlathrobium gen. n.}

Type species: Lathrobium lobrathiforme Assing, 2012

Etymology:

The name (gender: neuter) is composed of Sina, the ancient name for China, and the generic name Lathrobium. It alludes to the fact that the genus has been recorded only from China and to the hypothesized close phylogenetic affiliations with Lathrobium.

\section{Description:}

Species of moderately large size; body length 7.4-8.0 mm; length of forebody 3.8-4.4 mm. Habitus as in Figs 58, 72. Coloration characteristic: body black, elytra posteriorly with a defined orange spot and sometimes with the humeral angles diffusely reddish; legs and antennae of variable coloration.

Head (Figs 59, 73) of distinctive morphology, strongly transverse, at least approximately 1.15 times as broad as long, broadest across eyes; lateral margins behind eyes subparallel or weakly converging in dorsal view; posterior angles rounded, but noticeable; neck approximately half the width of head; dorsal surface uneven, with more or less distinct elevations and/or impressions; punctation areolate, coarse, and dense; interstices reduced to narrow ridges, with or without shallow microsculpture; vertex and/or antero-median dorsal portion usually with partly sparser and irregularly spaced punctures; anterior margin of frons impunctate; ventral aspect (Fig. 66) with shallow microsculpture and with much sparser punctation, interstices on average broader than diameter of punctures; gular sutures rather broadly separated, area between sutures impunctate; genal carinae absent. Eyes strongly bulging, composed of numerous fine ommatidia, longer than postocular region, and 0.7-0.9 times as long as distance from posterior margin of eye to neck. Antenna (Figs 60, 74) moderately slender; antennomeres I-III distinctly oblong, IV weakly oblong, and V-X weakly oblong or about as broad as long. Maxillary palpus (Fig. 69) slender, palpomere III approximately three times as long as broad; palpomere IV needle-shaped and slender, approximately as long as width of palpomere III. Labium (Figs 70-71) with relatively slender palpi, with oblong palpomeres I and II, and with needle-shaped, rather long palpomere III. Mandibles (Fig. 67) as in Lathrobium. Labrum (Fig. 68) deeply bilobed.

Pronotum (Figs 59, 73) rather short, 1.08-1.16 times as long as broad and 0.91-0.98 times as broad as head, widest anteriorly or in the middle; lateral margins straight 
to distinctly convex in dorsal view; punctation sparse to moderately dense, but less dense than that of head; interstices without microsculpture and glossy; prosternum with pronounced and apically acute process posteriorly.

Elytra (Figs 59, 73) moderately long, 0.90-0.97 times as long as pronotum; humeral angles pronounced; suture elevated and forming a rather distinct keel; supramarginal line absent; punctation moderately coarse, moderately sparse to dense, and not seriate; interstices without microsculpture. Hind wings presumably fully developed (examined only in S. iniquum). Mesoventrite approximately as long as broad, along middle with pronounced and anteriorly strongly projecting keel and with acute posterior process; metaventrite sparsely and finely punctate, with shallow microsculpture, and glossy. Protarsomeres I-IV distinctly dilated in both sexes. Metatarsomere I shorter than II.

Abdomen as broad as, or slightly narrower than elytra; segments III-VI of subequal width; punctation moderately coarse to fine and moderately sparse to dense; tergite VII with palisade fringe; tergite VIII without sexual dimorphism and with convex posterior margin; sternite III with pronounced, sharply elevated median keel not reaching posterior margin of sternite; tergites IX and $\mathrm{X}$ with sexual dimorphism, postero-lateral processes of tergite IX apically with spine-like process.

$0^{*}$ : tergite IX relatively short and broad, antero-median portion undivided in the middle, postero-lateral processes short; tergite $\mathrm{X}$ shorter than antero-median portion of tergite IX; sternites IV-VI with or without median impressions and modified pubescence; sternite VII (Figs 61, 75) strongly transverse, with pronounced postero-median impression, with or without modified pubescence, anterior margin without convex median projection; sternite VIII (Figs 62, 76) transverse, posterior excision moderately deep and anteriorly rounded; sternite IX (Figs 63, 77) asymmetric and anteriorly truncate, of similar shape as in Lathrobium; aedeagus (Figs 64-65, 78-79) symmetric, ventral process dorso-ventrally flattened, not separated from aedeagal capsule; dorsal plate weakly sclerotized, lamellate and subdivided into an apical and a basal portion; internal sac with or without a membranous tube; parameres absent.

\%: tergite IX divided along the middle and with relatively short postero-lateral processes (AssING 2012a: figure 328); tergite $\mathrm{X}$ longer than antero-median portion of tergite IX; sternite VIII with convex posterior margin (Assing 2012a: figure 327), posterior portion with short yellow setae, but without micropubescence (Fig. 80).

\section{Comparative notes:}

Among the Lathrobiina, Sinlathrobium is readily identified by external characters alone, particularly the strongly transverse head with dense and somewhat areolate punctation and an uneven dorsal surface, the large and strongly bulging eyes, and by the coloration of the elytra. The coloration resembles that of some species of Lobrathium and Tetartopeus. From the former, the new genus additionally differs by the absence of a supramarginal line of the elytra, the absence of short and stout black setae on the male sternites VII and VIII (Lobrathium: usually present at least on sternite VIII), the presence of a sexual dimorphism of tergites IX and X, and the different morphology of the aedeagus (Lobrathium: ventral process of different shape, more or less strongly separated from remainder of aedeagus). From Tetartopeus, it is additionally distinguished by the broader neck, the different punctation of the elytra, the less dense punctation and pubescence of the abdomen, and by the completely different sexual characters.

Among the genera currently attributed to the Lathrobiina, Sinlathrobium is most similar to Lathrobium in most characters, e.g., the morphology of the mouthparts, the broad neck, the absence of a supramarginal line of the elytra, the punctation of the pronotum, elytra, and the abdomen, the ventral aspect of the head, thorax, and abdomen, and the presence of a sexual dimorphism of tergites IX and X. In Lathrobium, however, the head is of different morphology (different shape, less transverse, without distinct elevations or impressions; in species with a distinctly transverse head, the latter is usually dilated posteriad), the eyes are much less convex, the mesoventrite is transverse, the pronotum is usually more oblong, the anterior margin of the male sternite VII usually has a convex median projection, the ventral process of the aedeagus is somewhat separated from the aedeagal capsule (at least at the apex) and usually more or less distinctly curved ventrad, the aedeagus usually has distinct internal structures (except for some species and species groups with highly derived aedeagi), and the female sternite VIII is of different chaetotaxy (posterior portion with micropubescence). Moreover, a female tergite IX with a divided antero-median portion is known only from few species groups in Lathrobium (Assing 2013).

Based on the conspicuously derived head morphology, the synapomorphically derived modifications of the male sternites III-VIII, the similar morphology of the aedeagus, and numerous other similarities, the monophyly of Sinlathrobium is beyond doubt. The problem is identifying synapomorphies constituting the morphology of Lathrobium, its hypothesized adelphotaxon. As can be expected with a megadiverse taxon, character diverstity is enormous in Lathrobium, particularly regarding the sexual characters. Regarding external morphology, however, Lathrobium is remarkably constant and always readily identified. Species with a faintly similar head morphology and coloration are unknown in this genus, nor do the sexual or other external characters suggest a closer relationship to any of the species groups of Lathrobium known from China or from other regions in the Palaearc- 
tic region. These observations suggest that Sinlathrobium is not nested within Lathrobium, but forms a separate lineage.

Like the species of Elytrobium, Sinlathrobium species seem to have a cryptic habitat. Three of the four species are currently represented only by their respective holotypes, and the fourth species has been recorded only from one locality.

\section{Distribution and natural history:}

The currently known distribution of the four species of Sinlathrobium is confined to China (Map 2). Despite the presumably fully developed hind wings, there is no evidence suggesting that any of the four species are widespread; each of them is known from only one locality. The species have been sifted from leaf litter and moss in mixed and old deciduous forests and in a creek valley with Salix, Rhododendron, and other deciduous bushes at altitudes of 1800-3050 m.

Sinlathrobium lobrathiforme (Assing, 2012), comb. n. (Figs 66-71, 80,Map 2)

\section{Comment:}

This species is known only from one locality in the northern Gaoligong Shan, northwest Yunnan, close to the border with Myanmar (Assing 2012a, 2013) (Map 2). The mouthparts, the ventral aspect of the head, and the female sternite VIII are illustrated in Figs 66-71, 80. For illustrations of the external and the male sexual characters see Assing (2012a).

\section{Sinlathrobium lobrathioides (Assing, 2012), comb. n. (Map 2)}

\section{Comment:}

This species is known only from the holotype, which was collected in the Jinfo Shan in the south of Chongqing province, close to the border with Guizhou (Map 2). For illustrations of the external and the male sexual characters see Assing (2012a).

\section{Sinlathrobium densepunctatum sp. n. (Figs 58-65,Map 2)}

\section{Type material:}

Holotype $0^{*}$ : "CHINA Sichuan pass Tianquan-Luding $3000 \mathrm{~m}, 29^{\circ} 51.44^{\prime} \mathrm{N} 102^{\circ} 16.48^{\prime} \mathrm{E}$ 7.VI.2001, M. Janata / Holotypus o Sinlathrobium densepunctatum sp. n., det. V. Assing 2013" (cAss).

\section{Etymology:}

The specific epithet (Latin, adjective) refers to the densely punctate abdomen.

\section{Description:}

Body length $7.7 \mathrm{~mm}$; length of forebody $4.1 \mathrm{~mm}$. Habitus as in Fig. 58. Coloration: body black, elytra with rather extensive orange spot in postero-lateral angles, this spot reaching posterior and lateral margins, but not suture, humeral angles diffusely and indistinctly dark-reddish; legs with the femora blackish, the tibiae brown, and the tarsi reddish; antennae dark-brown, with antennomere I blackish and the bases of II and III reddish.

Head (Fig. 59) 1.17 times as broad as long, broadest across eyes, tapering behind eyes; dorsal surface between eyes uneven, in the middle with densely punctate impression; punctation coarse, dense, and somewhat areolate; interstices reduced to narrow ridges, with distinct microreticulation and nearly matt. Eyes strongly bulging, approximately 0.8 times as long as postocular region from posterior margin of eye to neck in dorsal view. Antenna (Fig. 60) $2.3 \mathrm{~mm}$ long; antennomeres IV-VIII distinctly, IX-X weakly oblong.

Pronotum (Fig. 59) 1.13 times as long as broad and 0.93 times as broad as head, distinctly convex in crosssection, broadest slightly before middle; lateral margins convex in dorsal view; punctation coarse, very dense in anterior third, somewhat less dense posteriorly; interstices glossy, without microsculpture; impunctate midline narrow and confined to posterior two-thirds of pronotum.

Elytra (Fig. 59) 0.95 times as long as pronotum; punctation moderately dense, much finer than that of head and pronotum; interstices without microsculpture. Metatibia rather short, $1.1 \mathrm{~mm}$ long.

Abdomen slightly narrower than elytra; tergites III-IV anteriorly with coarse punctures, remainder of tergites III-VI with very fine and dense punctation, tergites VII-VIII with distinctly sparser punctation; posterior margin of tergite VII with palisade fringe.

$0^{*}$ : sternites III-VI without median impressions; sternite VII (Fig. 61) strongly transverse, 2.0 times as broad as long, with distinct postero-median impression, this impression with sparse black setae, near posterior margin on either side of postero-median impression with distinct transverse cluster of numerous stout black setae; sternite VIII (Fig. 62) transverse and with postero-median impression, postero-median portion without setae, posterior excision shallow; aedeagus (Figs 64-65) $1.1 \mathrm{~mm}$ long and symmetric; ventral process short and broad in ventral view; dorsal plate weakly sclerotized, apical portion broad, basal portion short and narrow. 


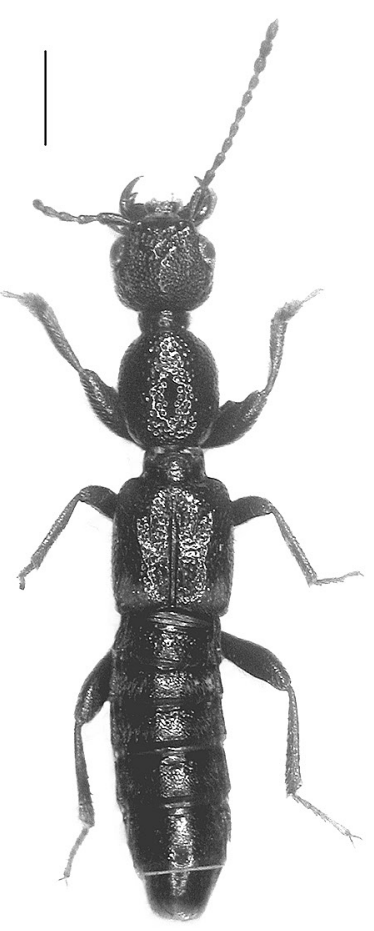

58

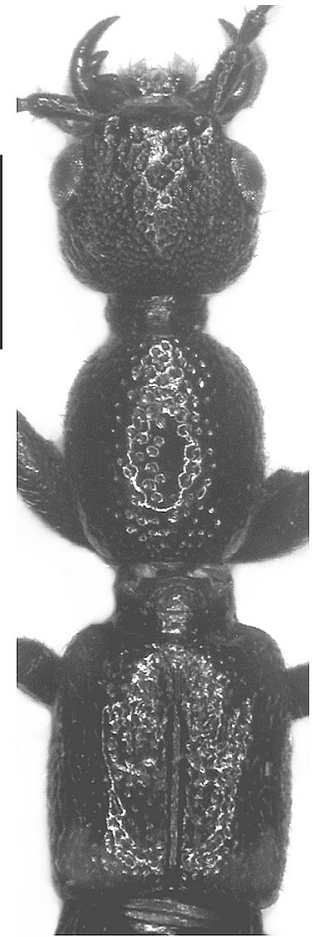

59

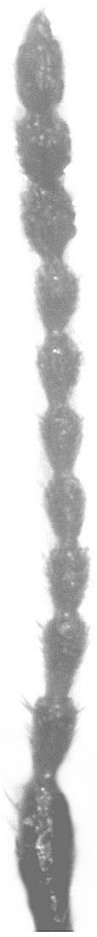

60

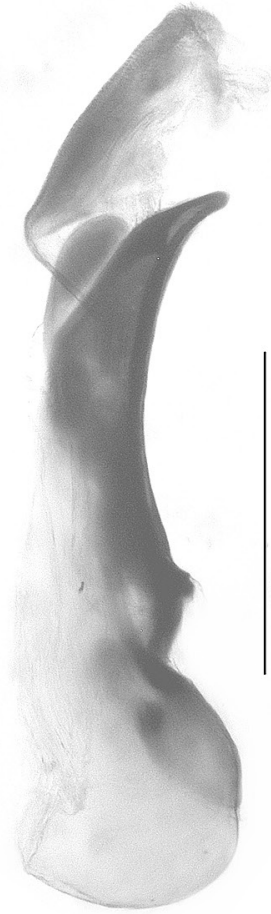

64

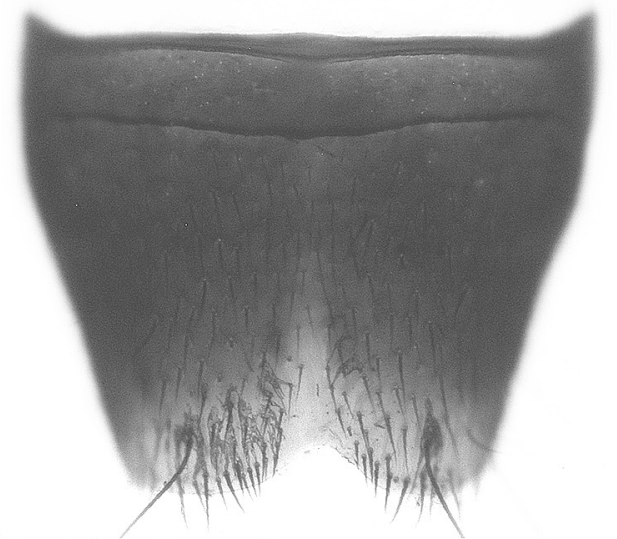

62

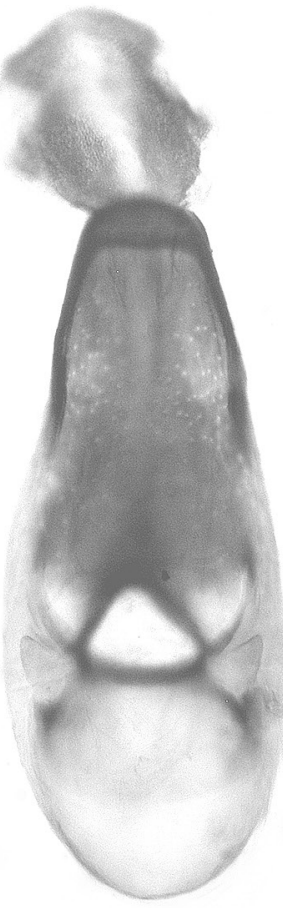

65

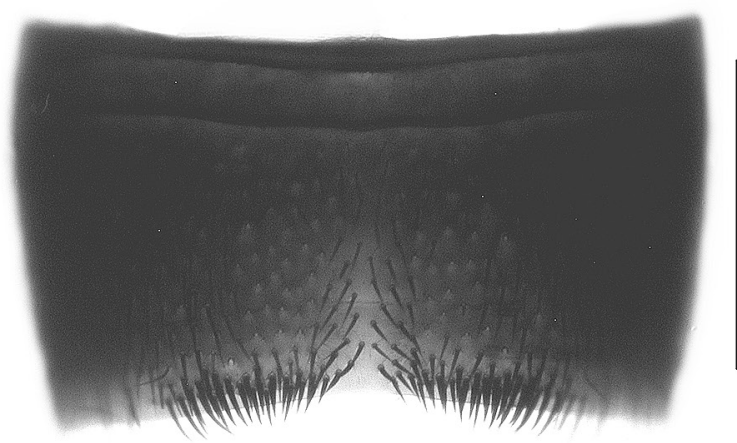

61

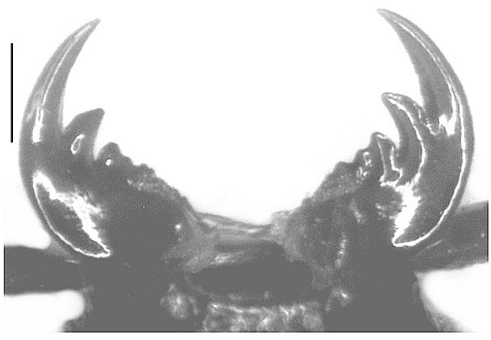

67

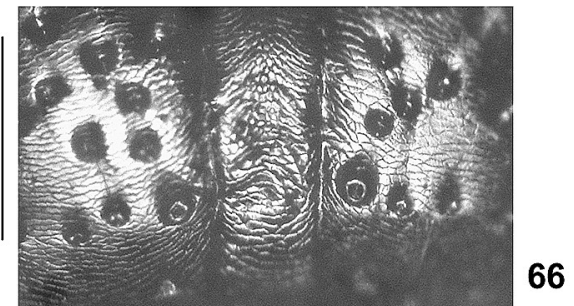

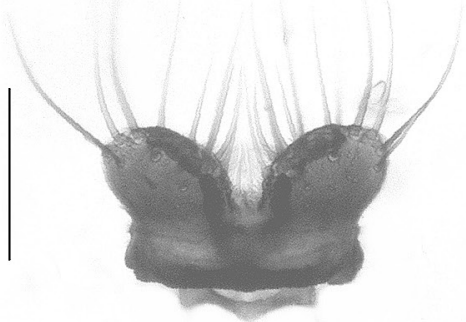

68

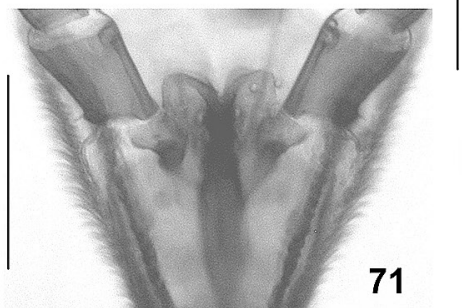

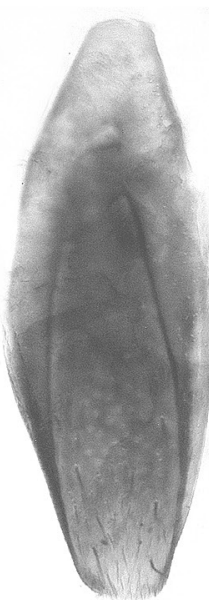

63

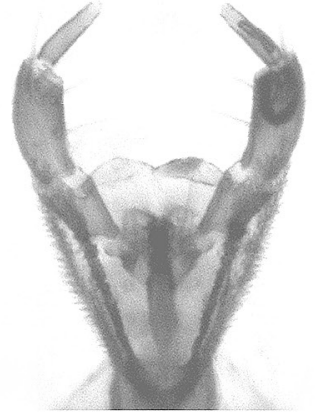

70

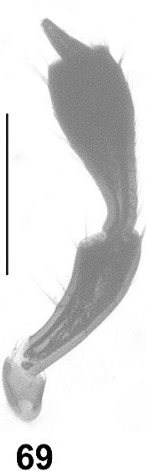

Figs 58-71: Sinlathrobium densepunctatum sp. n. (58-65) and S. lobrathiforme (Assing) (66-71): habitus (58); forebody (59); antenna (60); male sternite VII (61); male sternite VIII (62); male sternite IX (63); aedeagus in lateral and in ventral view (64-65); median portion of ventral aspect of head (66); mandibles in ventral view (67); labrum (68); maxillary palpus (69); labium (70); ligula (71). Scale bars: 58-59: $1.0 \mathrm{~mm}$; 60-65: 0.5 mm; 66-70: $0.2 \mathrm{~mm}$; 71: $0.1 \mathrm{~mm}$ 
क : unknown.

\section{Comparative notes:}

Sinlathrobium densepunctatum is easily distinguished from its congeners by the convex lateral margins of the pronotum in dorsal view, shorter tibiae, the finer and sparser punctation of the elytra, darker legs, the conspicuously dense and fine punctation of the abdomen, the more strongly transverse male sternite VII with a posterior pair of pronounced transverse clusters of stout black setae, the shallower posterior excision of the male sternite VIII, and by the shorter and broader ventral process of the aedeagus in ventral view.

\section{Distribution and natural history:}

The type locality is situated approximately $8 \mathrm{~km}$ to the southeast of Luding in western Sichuan (Map 2), at an altitude of $3000 \mathrm{~m}$. Additional data are not available.

\section{Sinlathrobium iniquum sp. n.}

(Figs 72-79)

\section{Type material:}

Holotype ơ: "CHINA-YUNNAN, Yanmen, 13.6.23.6.2005, lgt. E. Kučera / Holotypus o Sinlathrobium iniquum sp. n., det. V. Assing 2013” (cAss).

\section{Etymology:}

The specific epithet (Latin, adjective: uneven) alludes to presence of impressions and elevations on the head and the elytra.

\section{Description:}

Body length $8.0 \mathrm{~mm}$; length of forebody $4.4 \mathrm{~mm}$. Habitus as in Fig. 72. Coloration: body black, elytra with rather extensive orange spot in postero-lateral angles, this spot reaching posterior and lateral margins, but not suture; legs with the femora blackish, the tibiae blackish-brown, and the tarsi reddish; antennae dark-brown.

Head (Fig. 73) 1.15 times as broad as long, broadest across eyes; lateral margins behind eyes very weakly converging, nearly parallel in dorsal view; dorsal surface uneven, vertex with smooth median elevation, between eyes with two impressions near dorsal margins of eyes, frons with three small impressions; punctation coarse, dense in lateral and posterior portions of dorsal surface; median dorsal portion and frons with impunctate or more sparsely punctate areas; interstices without microsculpture and glossy. Eyes strongly bulging, approximately 0.8 times as long as postocular region from posterior margin of eye to neck in dorsal view. Antenna (Fig. 74) $2.2 \mathrm{~mm}$ long; antennomeres IV-V weakly oblong, VI-X as broad as long.

Pronotum (Fig. 73) weakly oblong, 1.08 times as long as broad and 0.98 times as broad as head, distinctly convex in

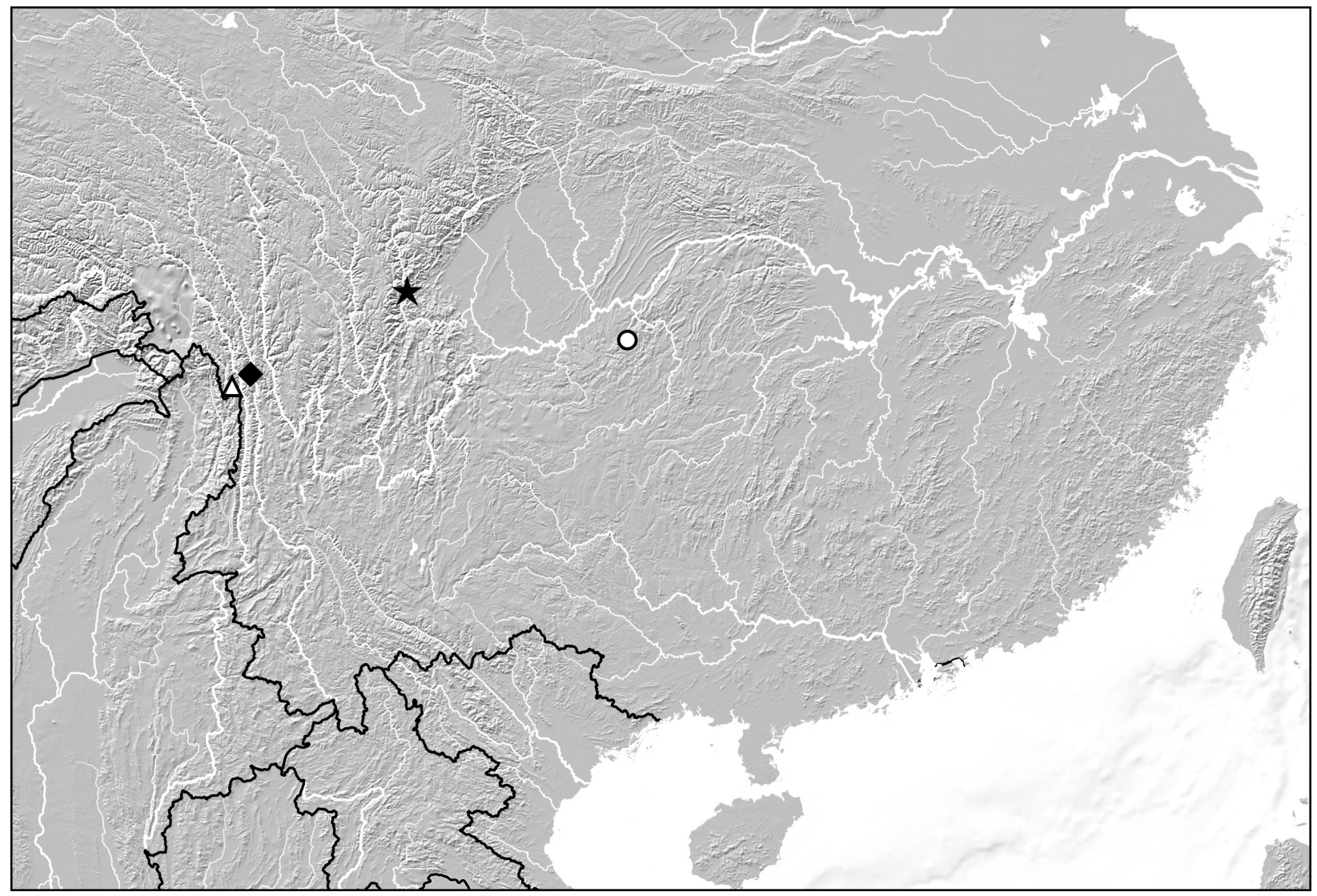

Map 2: Distribution of Sinlathrobium gen. n. in China: S. lobrathiforme (Assing) (triangle); S. iniquum sp. n. (diamond); E. densepunctatum sp. n. (star); S. lobrathioides (Assing) (circle). 
cross-section, broadest anteriorly; lateral margins convex in dorsal view; punctation coarse and moderately dense; interstices glossy, without microsculpture; impunctate midline confined to posterior third of pronotum.

Elytra (Fig. 73) 0.97 times as long as pronotum; punctation moderately dense, coarse, but shallow, partly weakly defined; disc uneven, with shallow, slightly diagonal longitudinal depressions. Metatibia $1.2 \mathrm{~mm}$ long.

Abdomen slightly narrower than elytra; punctation distinct and moderately dense, slightly sparser on tergites VII-VIII than on tergites III-VI; posterior margin of tergite VII with palisade fringe.

$\sigma^{\text {t: }}$ sternites III-VI with shallow median impressions; sternite VII (Fig. 75) strongly transverse, 1.8 times as broad as long, with distinct postero-median impression,
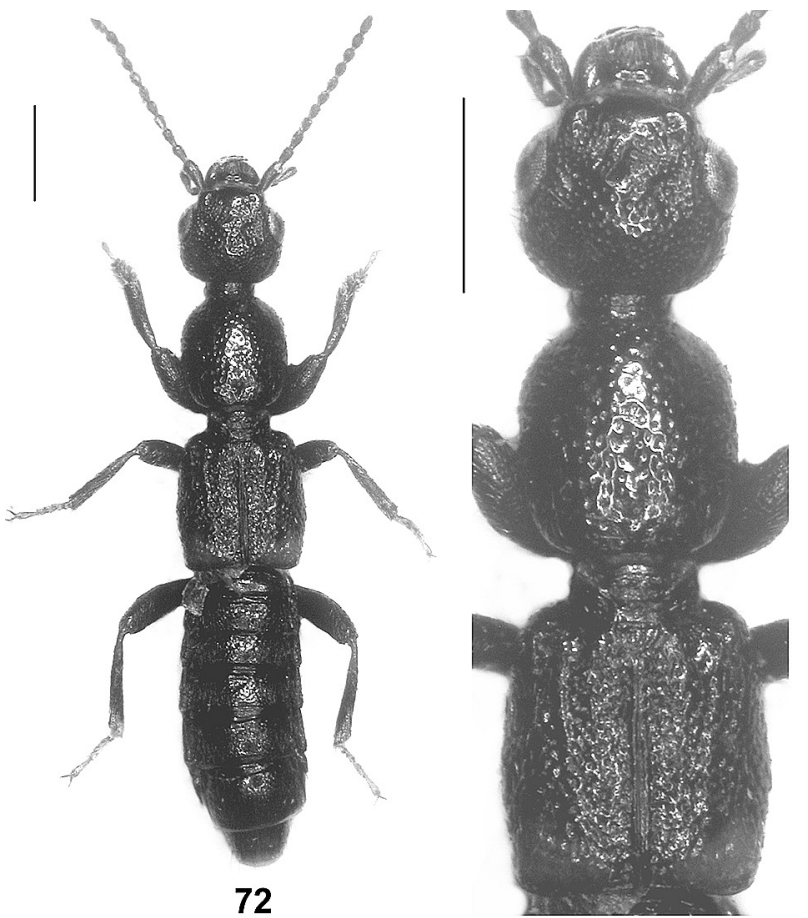

73

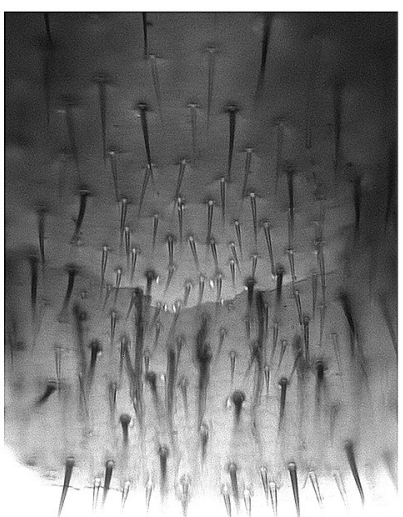

80

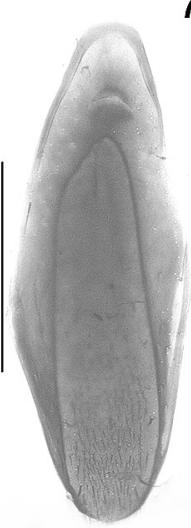

77

this impression without setae in the middle and posteriorly; postero-lateral portions with unmodified and not particularly dense dark setae, posterior margin weakly concave; sternite VIII (Fig. 76) transverse and with postero-median impression, postero-median portion without setae, posterior excision moderately deep; aedeagus (Figs 78-79) $1.4 \mathrm{~mm}$ long and symmetric; ventral process in the middle conspicuously sculptured, apically acute in ventral view; dorsal plate reduced, weakly sclerotized, lamellate, apical portion small, basal portion minute; internal sac with membranous structure.

q: unknown.

\section{Comparative notes:}

Sinlathrobium iniquum differs from all its congeners by the short and broad pronotum, the glossy elevations on the head, the uneven surface of the elytra, the shape and
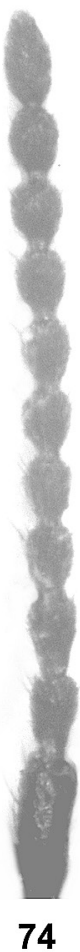

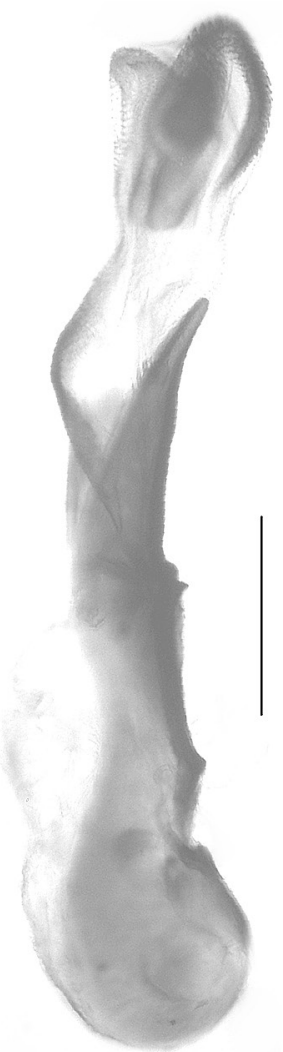

78

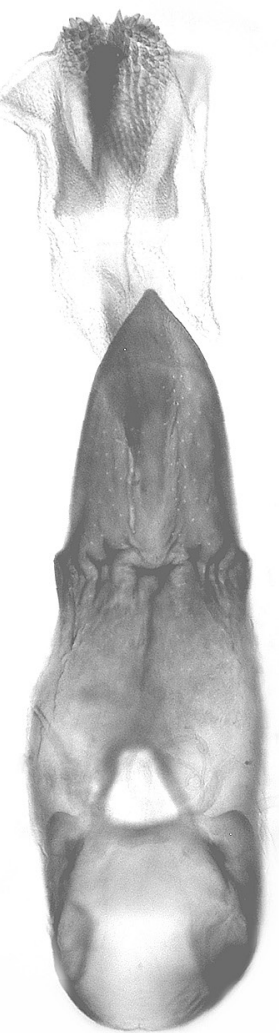

79

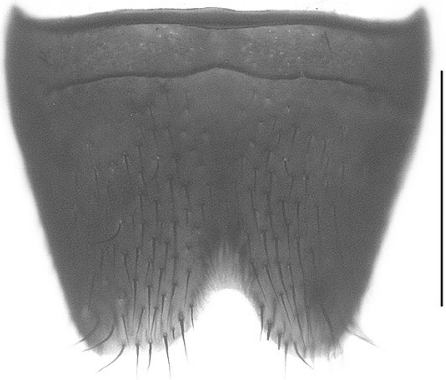

76

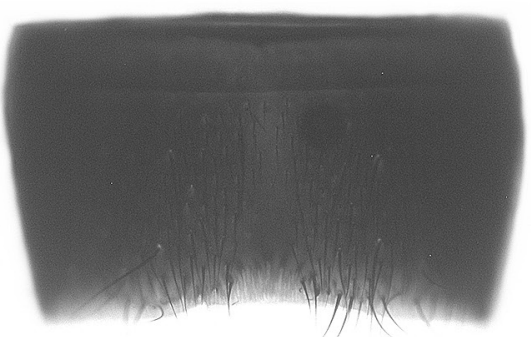

75

Figs 72-80: Sinlathrobium iniquum sp. n. (72-79) and S. lobrathiforme (Assing) (80): habitus (72); forebody (73); antenna (74); male sternite VII (75); male sternite VIII (76); male sternite IX (77); aedeagus in lateral and in ventral view (78-79); postero-median portion of female sternite VIII (80). Scale bars: 72-73: $1.0 \mathrm{~mm}$; 74-79: 0.5 mm; 80: 0.1 mm. 


\section{Key to the species of Sinlathrobium}

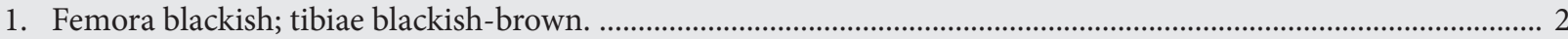

Femora reddish-brown to brown; tibiae reddish.

2. Median dorsal portion of head densely punctate and nearly matt, without distinct elevations and with a small median impression (Fig. 59). Antennomeres VI-X noticeably oblong (Fig. 60). Elytra glossy and with smooth surface, with fine and moderately dense punctation (Fig. 59). Abdomen, except for the anterior portions of tergites III and IV, with very dense and fine punctation. Male sternite VII strongly transverse, 2.0 times as broad as long, posteriorly with a pair of transverse clusters of numerous stout black setae (Fig. 61). Male sternite VIII with shallow posterior excision (Fig. 62). Aedeagus (Figs 64-65) $1.1 \mathrm{~mm}$ long, with broad, short, and apically convex ventral process in ventral view; ventral process not conspicuously sculptured in the middle. China: western Sichuan.

densepunctatum sp. $\mathrm{n}$.

- Median dorsal portion of head with moderately dense punctation and glossy, with rather large median elevation and with pair of lateral impressions (Fig. 73). Antennomeres VI-X not oblong, at least as broad as long (Fig. 74). Elytra with subdued shine and with shallow longitudinal impressions (Fig. 73). Abdomen with less fine and less dense punctation. Male sternite VII approximately 1.8 times as broad as long and without conspicuous clusters of black setae posteriorly (Fig. 75). Male sternite VIII with deeper posterior excision (Fig. 76). Aedeagus (Figs 78-79) $1.4 \mathrm{~mm}$ long, with more slender and apically acute ventral process in ventral view; ventral process conspicuously sculptured in the middle. China: northwestern Yunnan.

iniquum sp. $\mathrm{n}$.

3. Forebody with coarser and on pronotum denser punctation; interstices on pronotum distinctly narrower than diameter of punctures, except for the posterior rudiment of an impunctate median band (Assing 2012a: figure 322); abdomen with coarser punctation. Male sternites IV-VI with median impressions. Male sternite VII with weakly defined pair of clusters of black setae posteriorly (Assing 2012a: figure 323). Aedeagus apically acute in ventral view and more slender in lateral view (Assing 2012a: figures 325-326). China: Yunnan: Gaoligong Shan. ....

lobrathiforme (Assing, 2012)

Forebody with less coarse and on pronotum sparser punctation; interstices on pronotum on average broader than diameter of punctures (Assing 2012a: figure 316); abdomen with finer punctation. Male sternites IV-VI without median impressions. Male sternite VII without clusters of black setae (Assing 2012a: figure 317). Aedeagus apically convex in ventral view and stouter in lateral view (Assing 2012a: figures 319-320). China: Chonqing: Jinfo Shan. ...

lobrathioides (AsSING, 2012)

chaetotaxy of the male sternite VII, and the morphology of the aedeagus.

\section{Distribution and natural history:}

The type locality is situated in northwestern Yunnan, near the Mekong river, at approximately $28^{\circ} 03^{\prime} \mathrm{N}$, $98^{\circ} 53^{\prime} \mathrm{E}$ (Map 2). It is located $46 \mathrm{~km}$ to the northeast of the type locality of $S$. lobrathiforme in the $\mathrm{Nu}$ Shan. The type localities of both species are separated by the Salween river valley. Additional data are not available.

\section{Acknowledgements}

I am indebted to the colleagues indicated in the material section for the loan of material under their care. In particular, I am grateful to Aleš Smetana and Michael Schülke for the generous gift of several holotypes. Benedikt Feldmann (Münster) proof-read the manuscript. 


\section{References}

Assing, V. 2009: New species and additional records of Lathrobium and Tetartopeus from the Palaearctic region (Coleoptera: Staphylinidae: Paederinae). Linzer Biologische Beiträge 41 (2): 1269-1283.

Assing, V. 2010a: On the Lathrobiina of Taiwan (Coleoptera: Staphylinidae: Paederinae). - Beiträge zur Entomologie, Keltern 60 (2): 301-361.

Assing, V. 2010b: A revision of Achenium (Coleoptera: Staphylinidae: Paederinae). - Nova Supplementa Entomologica 21: 1-190.

Assing, V. 2011: On some East Palaearctic Tetartopeus species (Coleoptera: Staphylinidae: Paederinae). Linzer Biologische Beiträge 43 (2): 1179-1197.

Assing, V. 2012a: A revision of East Palaearctic Lobrathium (Coleoptera: Staphylinidae: Paederinae). - Bonn Zoological Bulletin 61 (1): 49-128.

Assing, V. 2012b: The Pseudolathra species of the East Palaearctic and the Oriental regions (Coleoptera: Staphylinidae: Paederinae). - Beiträge zur Entomologie, Keltern 62 (2): 299-330.

Assing, V. 2013a: On the Lathrobium fauna of China V. New species and additional records from Yunnan. - Contributions to Entomology, Beiträge zur Entomologie 63 (1): 53-128.

Assing, V. 2013b: A revision of Pseudobium IV. Three new species, a new synonymy, and additional records (Coleoptera: Staphylinidae: Paederinae). - Linzer Biologische Beiträge 45 (1): 229-245.

Assing, V. in press a: On the Lathrobium fauna of Japan (Coleoptera: Staphylinidae: Paederinae). - Linzer Biologische Beiträge 45 (2) (2013).

Assing, V. in press b: On the Palaearctic and Oriental species of Scymbalium and Micrillus (Coleoptera: Staphylinidae: Paederinae). - Linzer Biologische Beiträge 45 (2) (2013).

Coiffait, H. 1982: Coléoptères Staphylinidae de la Région Paléarctique Occidentale. IV. Sous famille Paederinae. Tribu Paederini 1 (Paederi, Lathrobii). Supplement à la Nouvelle Revue d'Entomologie 12 (4): $1-440$
NaOmi, S.-I.; Kuranishi, R. B.; Saito, A. \& MaruYAMA, M. 2000: A list of the family Staphylinidae (Insecta: Coleoptera) collected during the biological expedition to the Kamchatka Peninsula and the North Kuril Islands in 1996 and 1997. - Natural History Research, Special Issue No. 7: 101-111.

Newton, A. F.; Thayer, M.-K.; Ashe, J. S. \& Chandler, D. S. 2001: Superfamily Staphylinoidea LATrEILle, 1802, Staphyliniformia LameERE, 1900; Brachelytra auctorum. 22. Staphylinidae LATreille, 1802. In: Arnett, R. H. Jr. \& Thomas, M. C.: American Beetles. Archostemata, Myxophaga, Adephaga, Polyphaga: Staphyliniformia. Volume 1. - CRC Press, Boca Raton etc.: 272-418.

PenG, Z.; LI, L.-Z. \& ZhaO, M.-J. 2012: Three new species of Lathrobium GravenHorst (Coleoptera: Staphylinidae: Paederinae) from Sichuan, Southwest China. - ZooKeys 205: 33-44.

Rougemont, G. M. DE 1997: Dysanabatium Bernhauer, 1915 (Insecta: Coleoptera: Staphylinidae) - an uncommon but widespread genus in the Oriental region. Annalen des Naturhistorischen Museums in Wien 99 B: $319-331$.

Sharp, D. S. 1889: The Staphylinidae of Japan. - The Annals and Magazine of Natural History (6) 3: 28-44, 108-121, 249-267, 319-334, 406-419, 463-476.

Smetana, A. 2004: Subfamily Paederinae Fleming, 1821. - In: Löbl, I. \& Smetana, A. (eds.): Catalogue of Palaearctic Coleoptera. Volume 2. Hydrophiloidea - Histeroidea - Staphylinoidea. - Stenstrup, Apollo Books: 579-624.

WATANABE, Y. 2012: Description of a new paederine genus Nipponolathrobium (Coleoptera, Staphylinidae) with two new species from Japan. - The Japanese Journal of Systematic Entomology 18 (2): 335-345. 